\title{
Spatio-temporal monitoring of humidity induced 3D displacements and strains in mounted and unmounted parchments
}

\author{
Athanasia Papanikolaou ${ }^{1 *} \mathbb{D}$, Dorota Dzik-Kruszelnicka ${ }^{2}$ and Malgorzata Kujawinska ${ }^{1}$
}

\begin{abstract}
The high hygroscopicity and heterogeneity of parchment make it particularly sensitive to changes in environmental conditions. The proper housing of a historical parchment, including mounting should mitigate the impact of the changes on the object. However, finding an appropriate mounting method requires detailed knowledge of the mechanical response of a parchment on the combined influence from environmental changes and forces introduced by the mounting. In this paper we present the capabilities of 3D digital image correlation (3D DIC) method implemented for full-field, spatio-temporal monitoring of displacements and strains in parchment exposed to environmental changes. We combine the measurement concept with the particular, critical task of evaluating the effectiveness of stabilising a single sheet of parchment mounted using elastic polyester strips. 3D DIC is implemented to record in non-invasive and non-contact way the full-field response of parchment mock-ups to fluctuations of the relative humidity $(\mathrm{RH})$ without interfering with the climatic chamber processes. We measure and compare the impact of fluctuating RH on unmounted and mounted parchment samples, through the full-field 3D measurements of dimensional changes at selected humidity levels, and through the local and global analysis of the samples' response (displacement/strains) in time. We had proven in quantitative and detailed way that the applied mount fully fulfils its task, namely reduce significantly the out-of-plane displacements and strains occurring in the parchment during RH changes in the range from 39 to $80 \%$. Our study also demonstrates the possibilities of using 3D DIC for the efficient support of conservation scientists in the development of storage, mounting, and treatment protocols for historical parchment.
\end{abstract}

Keywords: Parchment, Mounting, Relative humidity changes, 3D digital image correlation, Full-field monitoring, Displacements, Strain

\section{Introduction}

Since ancient and medieval times, parchments have been the carrier of a significant part of cultural heritage-the most important religious, literary, and scientific treatises of its time [1]. They can take the form of single sheets, scrolls, or books. As a processed biological structuredehaired, untanned, and taut (goat, sheep, or calf) skin,

\footnotetext{
*Correspondence: *Athanasia.Papanikolaou@pw.edu.pl

${ }^{1}$ Faculty of Mechatronics, Warsaw University of Technology, Warsaw, Poland

Full list of author information is available at the end of the article
}

parchment is a complex research matter that is the subject of studies within the framework of many international projects, including the EU projects such as MAP: Methods in the Microanalysis of Parchment, (SMT496-2101) [2, 3] IDAP: Improved Damage Assessment of Parchment (IDAP, EVK-CT-2001-00061)[4] and others $[5,6]$. Understanding the chemical and physical properties of the structure of parchment and the reasons for its degradation is both a challenge and a necessity for conservators and collectors.

High hygroscopicity and hydration properties are among the essential features of parchment [7-11].

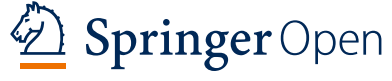

(c) The Author(s) 2022. Open Access This article is licensed under a Creative Commons Attribution 4.0 International License, which permits use, sharing, adaptation, distribution and reproduction in any medium or format, as long as you give appropriate credit to the original author(s) and the source, provide a link to the Creative Commons licence, and indicate if changes were made. The images or other third party material in this article are included in the article's Creative Commons licence, unless indicated otherwise in a credit line to the material. If material is not included in the article's Creative Commons licence and your intended use is not permitted by statutory regulation or exceeds the permitted use, you will need to obtain permission directly from the copyright holder. To view a copy of this licence, visit http://creativecommons.org/licenses/by/4.0/. The Creative Commons Public Domain Dedication waiver (http://creativeco mmons.org/publicdomain/zero/1.0/) applies to the data made available in this article, unless otherwise stated in a credit line to the data. 
Parchment's structure consists of collagen made up of a sequence of amino acids linked into a polypeptide chain whose spiralling triple structure quantitatively dominates the molecule $[6,12]$. The presence of amino acids with polar side chains determines the strongly hygroscopic nature of parchment $[6,11]$. Parchment's ability for water exchange (hygrometric change) depends on the relative humidity of the environment, the condition of collagen and its modification as a result of hydrolysis, hydrogen bond stability, and the rate of gelatine formation [6-9, 13-15]. Under the influence of water adsorption and desorption, parchment undergoes heterogeneous changes to its linear dimensions and thickness, as well as spatial deformations and tensile parameters [16]. Therefore, the knowledge on the interaction of parchment with environmental factors such as moisture is an important aspect for the preservation and storage of parchment-based artefacts.

Stabilising the structure of single sheets of parchment is a practical response to the specific needs of matter. Several research groups have considered the issues relating to the conservation mounting of parchment-based objects [17-26]. The traditional rigid mount on a frame/ stretcher does not compensate for the dimensional variations and the natural distortion of the membrane in fluctuating environmental conditions [27]. Because of this, various flexible mounting systems have been investigated since the 1980s. They mitigate the dimensional variations of the parchment, keeping it reasonably flat, by utilising twisted linen threads, which shrink in high $\mathrm{RH}$ and expand in low RH [18, 21, 27, 28]; Japanese paper, which responds similarly to parchment in various forms of tabs [18], twisted tabs or false margins [17]; or stainless steel springs [29]. One of the most promising parchment mounting systems is using elastic polyester strips [18, 19]. It was proposed by the researchers of the Victoria \& Albert Museum, London and it has found not only practical application in conservation studios [30], but also became the subject of inspiring research by Duqueyroix N. et al. [26], in which the safety and performance of this method in fluctuating RH conditions was evaluated.

However, in our opinion, this promising solution requires further attention, especially in the context of the final modifications of the parchment mounting system, as well as the assessment of its capacity to handle parchment deformations and evaluating any additional tension in the membrane. In this paper, we focus on the metrological issues related to the dimensional and strain performance of parchment under relative humidity changes while unmounted and mounted in a system with elastic polyester strips.

Most of the publications dealing with moisture-related changes in parchment are focused on microstructural analysis [4, 14, 31, 32]. Limited information, to our knowledge, exists on quantitative, full-field monitoring of parchments and their mounting systems. The measurement methods are most often limited to dimensional studies by conventional techniques such as dimension measurement in three points and raking light photography [26] or more advanced approaches using laser scanning [16] or other 3D measurement methods [33]. Strain analysis is usually performed in a standard way at parchment samples subjected to load at a tensile machine [9, 33]. However, all these methods are not sufficient for in-depth, comprehensive, and in-situ assessment of the safety and efficiency of a parchment mounting during environmental changes.

Therefore, we propose to use full-field quantitative monitoring by means of digital image correlation method (DIC), which allows to evaluate the mechanical behaviour of the parchment in terms of out-of-plane and in-plane displacements as well as strains [34]. The advantage of this method is its non-invasive and non-contact character. It allows for real-time full field-of-view (FoV) recording of parchment responses for environmental changes according to the designed measurement scenario. This is a significant advantage over the existing, traditional methods, which allow measurements at a specific moment only, and often, they need to remove samples from the climatic chamber. An additional advantage of the proposed technique is the possibility to determine changes both on a global (e.g., Peak-to-Valley (P/V) of displacements and strains in total FoV) and local (displacements and strains at the selected points or regions) scales.

According to our best knowledge, this is the first time that DIC technique has been used to monitor and analyse a parchment behaviour under changing relative humidity conditions. Furthermore, we incorporate the selected measurement approach to assess the stabilization of a single sheet of parchment mounted by means of a flexible structure. During our research, we compared the behaviour of a stabilised sheet of parchment (mounted) with a free-standing one (unmounted). This significantly extends and deepens the existing knowledge on the impact of the fluctuating humidity conditions on the specific nature of parchment itself and estimates the suitability of the proposed mounting method. Investigations were supported by monitoring the performance of the selected hinges in the parchment mount.

It is also the ambition of this study to answer two important research questions related to both unmounted and mounted samples: (i) what is the scale of changes in terms of out-of-plane (W) and in-plane displacements $(\mathrm{U}, \mathrm{V})$ and how they are related to the features of the samples (the local thickness and fibre orientation) and to 
the strain distributions; and (ii) what is the spatio-temporal response (global and local) of the samples (in terms of displacement and strains) to the controlled RH fluctuations in time and how this knowledge can help in the future to optimise the mount performance and determine storage or exposition conditions. In the last part of this work, we demonstrate the applicability of the presented methodology in a case study of a historical manuscript subjected to environmental relative humidity fluctuation.

\section{Materials and methods}

\section{Parchment: description of the samples}

The main idea behind selecting proper materials was to mimic parchment-based objects, using new parchment of known origin, in an unmounted and mounted form. We obtained two relatively large samples from one selected and recognised area of the animal's skin. The similarity of both samples was also useful in further comparative studies of the mounted and unmounted models. It should also be mentioned that, at this stage of our research, we do not consider investigating separately the effect of additional coating layers (painted or printed) naturally present at historical parchment artefacts.

Although well described [1, 12, 35], the parchment manufacturing process has evolved over time, and it contains several essential phases. To a certain extent, modern parchment-making technology replicates basic processes such as soaking, liming, washing, and removing lime, and in the final stage, a parchment contains $85,4 \%$ collagen, $13 \%$ water, lime, and other components $[6,11,35]$. Consisting almost entirely of collagen, it is susceptible to bonding with polar molecules and highly liable to water damage [11]. It is worth noting that each subsequent stage of the manufacturing process leads to changes in collagen that affect its properties: liming means that the parchment absorbs and adsorbs water in humid conditions and loses water in drier conditions. It results in a change in rigidity from rigid to damp, but also significant contraction and expansion across all dimensions $[6,11$, 36].

In this research, we used goatskin parchment from the manufacturer Perskór [37], a material produced with the use of modern technology. Two sheets with dimensions of $200 \mathrm{~mm} \times 200 \mathrm{~mm}$ were cut with a scalpel. Both pieces were cut from the side area of the animal's skin (Fig. 1a), and they are further used as the samples for the investigations of unmounted $\left(\mathrm{S}_{\mathrm{u}}\right)$ and mounted parchment $\left(\mathrm{S}_{\mathrm{m}}\right)$ mock-ups.

In order to properly interpret the results of the measurements, it is necessary to gain comprehensive knowledge about the samples, including their surface pattern, the directional run of fibres, and parchment thickness, which can significantly influence the local displacements

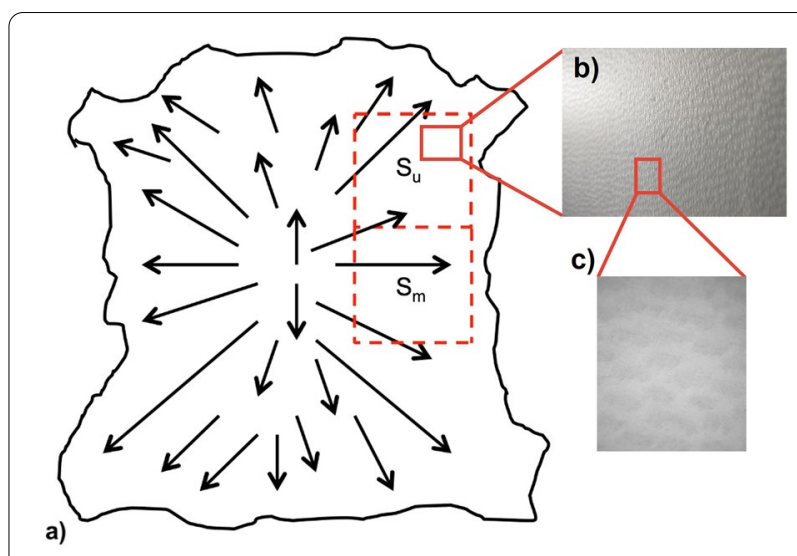

Fig. 1 The scheme of $\mathbf{a}$ the initial animal skin showing the directional run of fibres in the skin with the sample collection site marked by the red dotted square and, $\mathbf{b}$ a photo of the grain surface pattern in raking light and $\mathbf{c}$ a $40 \times$ magnified image of a selected area

and strains distribution. To describe the surface pattern and assess the directional run of fibres, the samples were analysed in different types of lightning (raking light, transmitted light). Goatskin surface pattern shows the regular alternating rows of fine and large follicles [36] as shown in Fig. $1 \mathrm{~b}$ and c. Hair growth occurs in accordance with the general fibres run. Due to morphogenesis, fibrils develop with the foetus, aligned along the main tension lines of extending backbone and legs [36] as indicated in Fig. 1a. The 3D weave of the fibre bundles is running parallel to the grain surface, therefore careful investigation of the grain surface at $S_{u}$ and $S_{m}$ samples defines the major direction of fibres in the parchments (Fig. 2). This initial knowledge about the sample is essential as this directional run of the fibres affects the physical properties of parchment $[6,35,36]$. The strength is better, and the flexibility is worse in the direction parallel with the general run of the fibres.

Despite the direction of the fibres, thinner and thicker parts, creases and discolouration areas are identified by visual inspection and indicated in Fig. 2. They can occur during the manufacturing process or even at the living stage. The crease on the outer grain may be caused by curving the parchment grain inwards or by the uniformity of the leather structure. Different transparency may result from small local thickness or gelatinisation of parchment. This cannot be definitely determined. We can assume that the thinnest areas are subject to the most substantial deformation; therefore, this information may be crucial for further interpretation of the results. The thickness of the samples was initially measured in a few selected points distributed over the total area and later with higher spatial frequency along the selected cross sections $\mathrm{L}_{\mathrm{Su}}$ and $\mathrm{L}_{\mathrm{Sm}}$, as shown in Fig. 2. The 


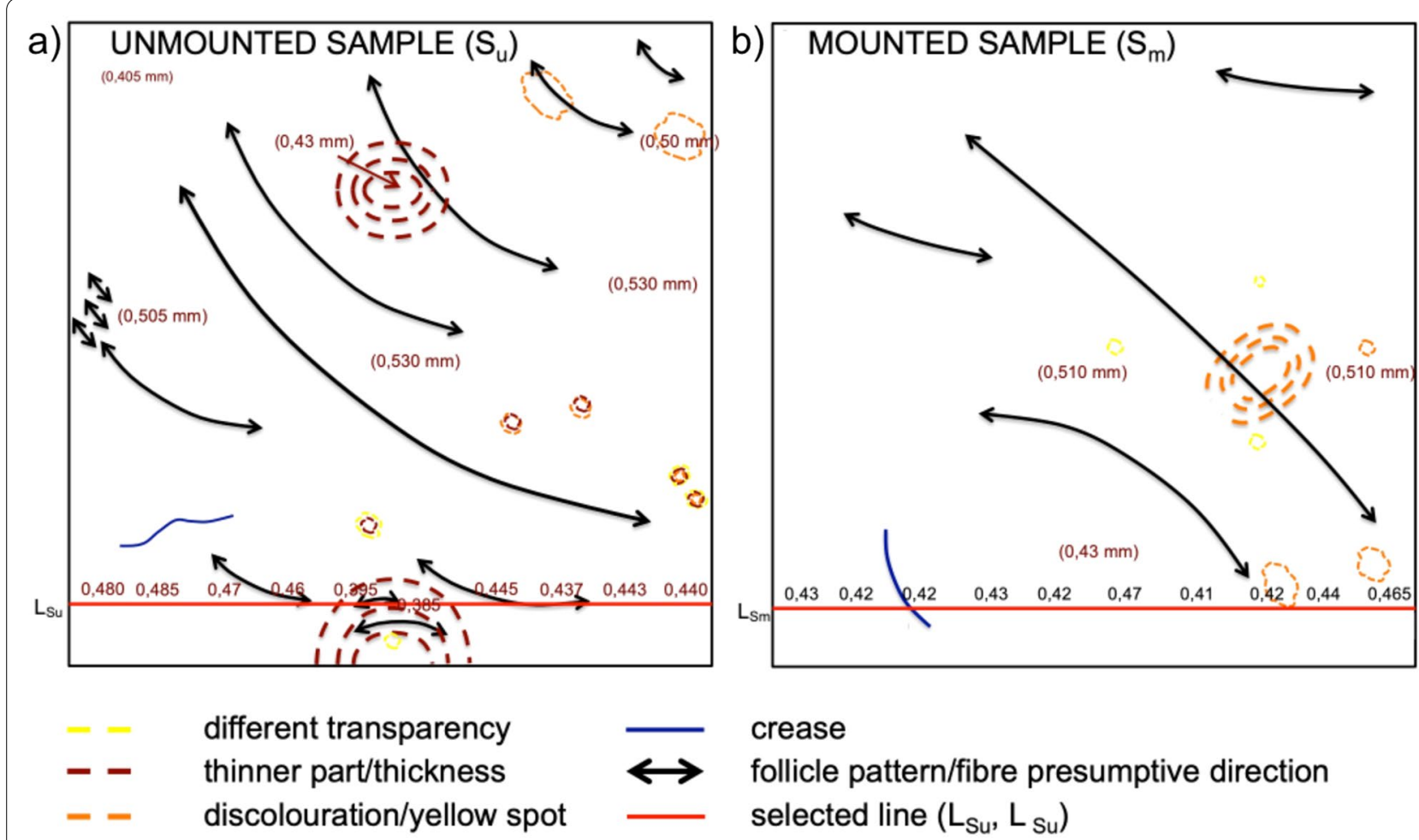

Fig. 2 The scheme of the samples with indication of the most important features: $\mathbf{a}$ the unmounted sample $\left(\mathrm{S}_{u}\right)$ and $\mathbf{b}$ the mounted sample $\left(\mathrm{S}_{\mathrm{m}}\right)$ from flesh/artificial pattern side. The red line indicates the cross sections $L_{s u}$ and $L_{S m}$ along which the sample thickness was measured each $20 \mathrm{~mm}$

measurements were carried out with VEB Feinmassgeraetewerk Freiberg DM100P thickness meter. The ranges of the thickness of both samples are similar; namely, it varies from $0.395 \mathrm{~mm}$ to $0.530 \mathrm{~mm}$ for the unmounted sample and from 0.430 to $0.510 \mathrm{~mm}$ for the mounted sample.

\section{Description of the mounting method}

To mount the parchment, we had implemented a system using elastic polyester strips founded on the method proposed by Victoria \& Albert Museum, London [18, 19] and enhanced by Duqueyroix N. et al. [26]. We had further modified the mock-up mount based on the research carried at the Academy of Fine Arts, in Warsaw [Aneta Kukuczka- Szarzec, unpublished observations]. The details are presented below and illustrated in Fig. 3. At first elastic strips (ES) were prepared. The material used was a chemically neutral polyester foil (without coatings) with a thickness of $75 \mu \mathrm{m}$ (source: Beskid Plus[38]). The strips were laser cut with a 600VN Laser with high precision. The suitable dimensions and geometry of

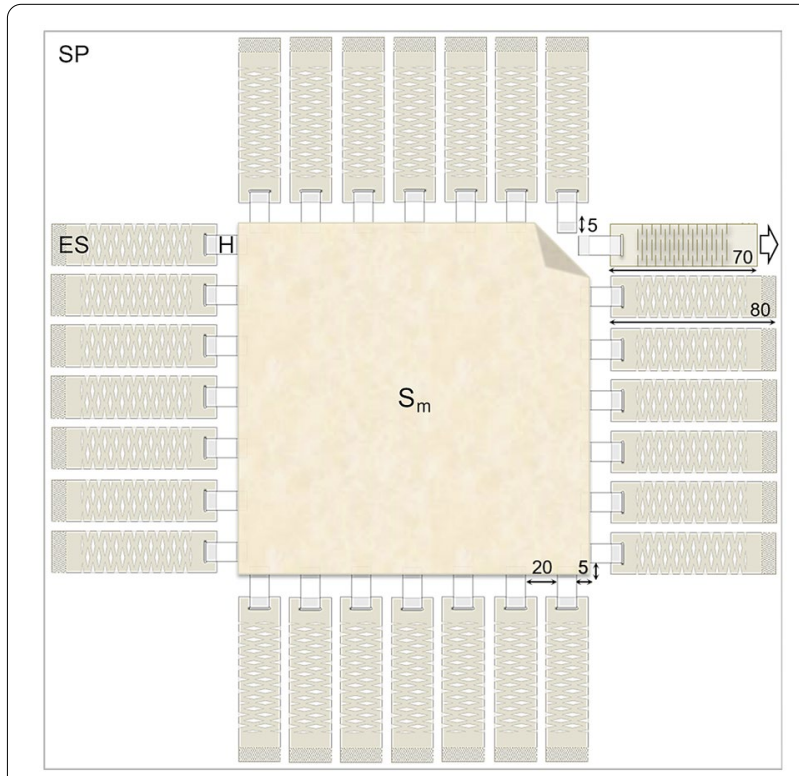

Fig. 3 Installation of parchment with elastic strips. Values given in $\mathrm{mm}$, the abbreviations explained in text 
the element enabled the strips to be flexible and adapt to the changing dimensions of the object and bound to the parchment and the mount. Next hinges, $\mathrm{H}$, with dimension $9 \mathrm{~mm} \times 25 \mathrm{~mm}$, were cut from Japanese kozo fibre paper ( $39 \mathrm{~g} / \mathrm{m}^{2}$, Hosokawa) in the direction of the fibres, then each of them was covered with a thermoplastic BEVA 371 Film. Subsequently, on the one side, the polyester strips were connected to the paper hinges by welding the previously applied glue with a hot iron. On the other side, BEVA 371 was attached in the same way, and it was later used to bind it to the mount. The mount for attaching the parchment sheet was prepared in the form of a multi-layer, honeycomb-structured cardboard $400 \mathrm{~mm} \times 400 \mathrm{~mm}$ panel (SP). The $14 \mathrm{~mm}$-thick, buffered mount, recommended by conservators, is made entirely of pure $\alpha$-cellulose fibres. It is lightweight and highly stabile. Finally, the mock-up montages were prepared. Flexible polyester strips were attached to the parchment with paper hinges $\left(\mathrm{S}_{\mathrm{m}}\right.$-H-ES) with a mixture of wheat starch paste $\left(15 \mathrm{~g} / 110 \mathrm{ml} \mathrm{H}_{2} \mathrm{O}\right)$ and isinglass $(10 \%)$ in a 1:1 ratio. 28 elastic strips, 7 on each side, were attached to the parchment sheet (Fig. 3). They were placed $10 \mathrm{~mm} \pm 0.5 \mathrm{~mm}$ apart. In the corners, the paper hinges were placed $5 \mathrm{~mm}$ from the edge of the sheet. The prepared parchment with the mount was placed on the cardboard panel. Next, symmetrically stretching the strips by $10 \mathrm{~mm}$ each, they were attached to the SP by welding the glue at the ends of the polyester fixings $\left(\mathrm{S}_{\mathrm{m}}\right.$-H-ES-SP) (Fig. 3).

\section{Digital image correlation}

Experiments were performed by means of digital image correlation (DIC), which is a non-contact, image-based optical method for full-field shape and displacement measurements with scalable dimensions, field of view and measurement accuracy, as well as flexibility in data acquisition frequency [34, 39]. 2D DIC and 3D DIC (also known as stereo-DIC) variations of the method are widely used and accepted in the field of experimental mechanics [40], industry [41, 42] and civil engineering $[43,44]$. The 3D DIC method has also been implemented for monitoring cultural heritage objects such as canvas paintings $[45,46]$.

The general operation diagram for 2D DIC and 3D DIC methods is shown in Fig. 4. 2D-DIC uses one camera to determine in-plane displacements $\mathrm{U}(\mathrm{x}, \mathrm{y})$ and $\mathrm{V}(\mathrm{x}, \mathrm{y})$, while 3D DIC uses two cameras for in-plane and out-ofplane $\mathrm{W}(\mathrm{x}, \mathrm{y})$ displacements and shape $(\mathrm{x}, \mathrm{y}, \mathrm{z})$.

The straightforward 2D DIC measurement procedure requires acquiring a set of images of an object subjected to mechanical or environmental load. The object has to exhibit a random texture (a unique pixel intensity pattern) on its surface. One of the images is selected as

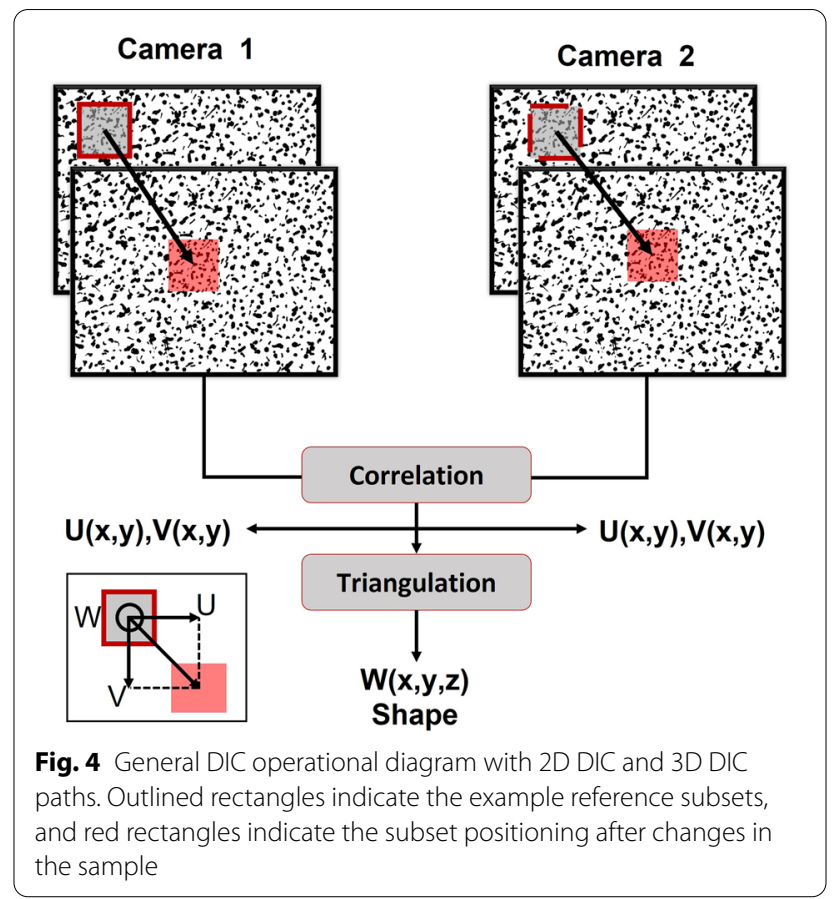

a reference image (in most cases, the image captured before the load is applied), and the remaining images are subjected to correlation analysis. The reference image is divided into small subsets. The subsets are subsequently matched against similar subsets in images acquired at different load states. Repeating the procedure for all subsets with a selected step yields in-plane displacements maps, which in the following steps can be used for calculations of strains [47].

To acquire accurate 2D DIC measurements, some strict requirements on the specimen deformation, loading device, and measuring system must be met [48]. If the test object is non-planar, or if 3D deformation occurs after loading, the 2D DIC method is no longer applicable. 3D DIC technique overcomes the measuring limitations of 2D DIC, using two synchronised cameras. Based on the principle of binocular stereovision, 3D DIC can accurately measure full-field 3D shape and in-plane and out-of-plane displacements of both planar and curved surfaces. Thus it is more useful and practical in real applications. In 3D DIC, the cameras capture sequential image pairs of a sample under varying loadings. A reference pair of images is selected, and the subsequent ones are used for the correlation analysis. In 3D DIC, the correspondence of the projection of physical points in the left and right images must be established using correlation algorithms (stereo matching). Together with the calibrated parameters of the stereo rig, 3D coordinates of measurement points are recovered with the classic triangulation 
method. Further, by subtracting the 3D coordinates of the same physical points at the initial state from those of deformed states, three displacement components ( $U$, $\mathrm{V}, \mathrm{W}$ ) caused by external loading can be computed. This is done by temporal matching in which the same physical points in the consecutive images recorded by the same (left or right) camera at different times or states are tracked. Temporal matching can be directly implemented using the well-established subset-based 2D DIC algorithm [34].

As mentioned above, the necessary condition for DIC method implementation is a random texture (a speckle pattern) on the surface of the object. The speckle pattern is, in most cases, introduced artificially to an object using either additive or subtractive approaches [49]; however, some of the objects have a natural texture which is sufficient for successful DIC measurements [46, 50, 51].

The samples studied herein are mock-ups without strong surface texture for correlation (Fig. 1c), and therefore the application of a speckle pattern on their surface was necessary. The expected accuracy of displacements measurement depends on the quality of the random texture and the optical configuration of the system and camera parameters (number and size of pixels). In general, it can be estimated by the fraction of the pixel size at the object plane $\left(\Delta_{\text {obj }}\right)$, namely: for in-plane displacements, it equals approximately $\Delta_{\text {obj }} / 40$ and for out-of-plane displacements $-\Delta_{\text {obj }} / 20$ [34].

In our experiment, the pattern was generated manually by dense, random application of spots of different diameters (Fig. $5 b$ and c). For this purpose, we used: uni-ball PIN water-resistant pens of different diameters: $0.03 \mathrm{~mm}$; $0.1 \mathrm{~mm} ; 0.4 \mathrm{~mm} ; 0.7 \mathrm{~mm}$. The pattern was applied on the flesh side of the parchment, as this side was almost invariably used for recording documents in Western Europe (legal documents - charters, deeds indentures, or music manuscripts) [11]. Additionally, three elastic stripes were artificially textured partially to enable monitoring of their behaviour during the experiment (the areas are marked as red rectangles in Fig. 5c).

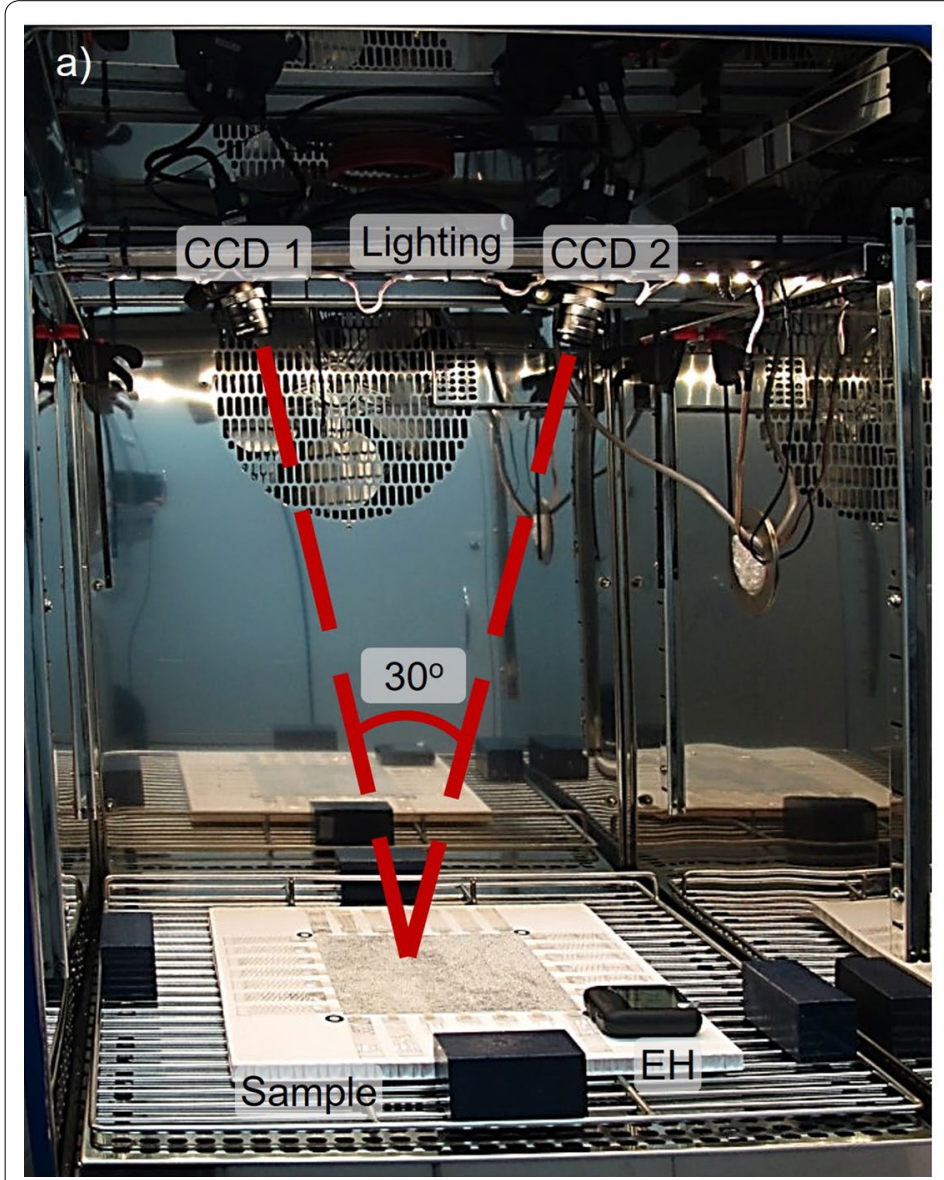

b)

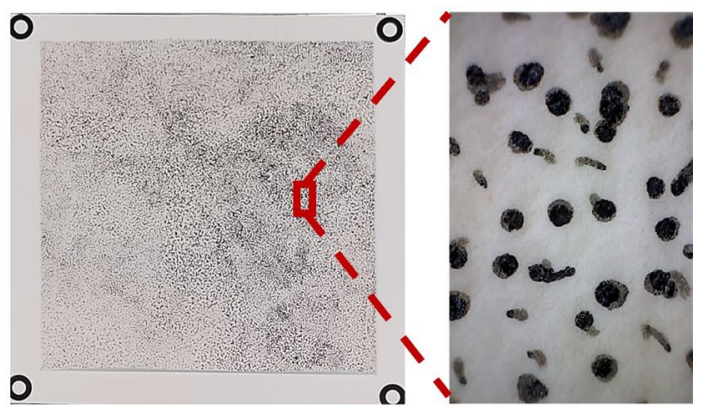

c)

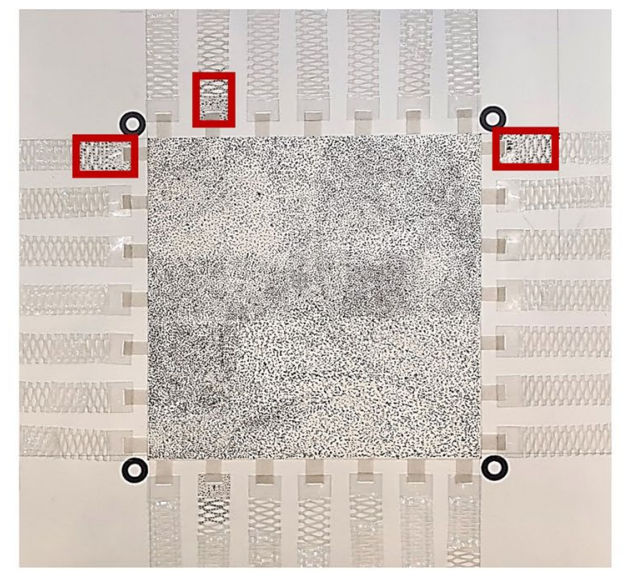

Fig. 5 Experimental set-up: a the photo of the system in the climatic chamber, the positioning of the detectors, lighting, sample and external hygrometer are indicated, $\mathbf{b}$ unmounted sample $\left(\mathrm{S}_{\mathrm{u}}\right)$ with artificial texture and magnification $\times 40 \mathbf{c}$ sample $\left(\mathrm{S}_{\mathrm{m}}\right)$ with artificial texture and the mounting system 


\section{Experimental apparatus}

The 3D DIC apparatus used during our experiments consists of two monochrome cameras (Point Grey model GRAS-50S5M-C) with a resolution of $2448 \times 2048$ pixels and $16 \mathrm{~mm}$ focal length objectives. The cameras were fixed to an aluminium rod with the optical axis crossing at the central point of the Field of View (FoV) under an angle of $28.6 \mathrm{deg}$ (Fig. 5a). The 3D DIC system was positioned inside a CTS C-20/350 climate chamber [52], which allows controlling the measurement of the atmospheric conditions of the samples in the following ranges: humidity from 10 to $98 \%$ and temperature from $-20{ }^{\circ} \mathrm{C}$ to $180{ }^{\circ} \mathrm{C}$. The total $\mathrm{FoV}$ was $305 \mathrm{~mm} \times 250 \mathrm{~mm}$ resulting in the size of the pixel in the object plane equal to $\Delta_{\text {obj }}=0.12 \mathrm{~mm}$. The sample was illuminated with a commercial LED stripe, which was fixed to the aluminium rod. The samples, in both the mounted and unmounted cases, were positioned freely at the bottom rack, as shown in Fig. 5a. An additional external hygrometer $(\mathrm{EH})$ was placed inside the chamber next to the sample in order to precisely monitor the $\mathrm{RH}$ changes. Throughout the experiment, the temperature inside the chamber was kept constant at $20{ }^{\circ} \mathrm{C}$. The subset and step parameters needed for DIC analysis were selected for 37 and 7 pixels, respectively.

A portable computer equipped with appropriate custom-made software (developed by Warsaw University of Technology-WUT) was used for the data capturing. The data analysis and visualisation were carried out using the Correlated Solutions, Vic-3D 7 [53] software. For statistical analysis and data post-processing, MATLAB was implemented. In the DIC calculations, we used the normalised sum of squared differences as the correlation criteria. The strains were calculated according to LaGrange strains [34] and with a filter of 35 pixels.

\section{$\mathrm{RH}$ scenario and designing of the experiment}

The fluctuation of RH and temperature induces dimensional changes in parchment. The goal of our study was to estimate the impact of fluctuating humidity conditions on the unmounted and mounted parchment samples through: (i) the full-field measurements of dimensional changes at selected humidity levels, and (ii) the local and global analysis of the samples' response (displacement/strains) in time. The implemented scenario for $\mathrm{RH}$ changes and the experimental conditions is close to those proposed in the literature and typically met in museums or archive facilities. The literature review demonstrates a variety of $\mathrm{RH}$ changes scenarios for modern parchments including the following $\mathrm{RH}$ steps: $20-95-20 \% \mathrm{RH}$ [54], 40-60-80\% RH, 40-80\% RH [55] 75-67-58-48-38-339\% RH [26], 35-70-35\% RH [6], 35-75\% RH [56]. During our experiments, we assumed humidity fluctuations starting from ambient conditions $\mathrm{T}=(20 \pm 2)^{\circ} \mathrm{C}$ and $\mathrm{RH}=(50 \pm 2) \%$. It correspond to the accepted, although disputable $[8,9,57]$, "one-size-fits-all collections" universal standard, which may reflect the actual fluctuations in museum or archive storage facilities. While various guidelines are provided regarding the conditions for storing parchment, the literature sometimes emphasises the lack of adequate underlying premises $[7,8]$. Based on the finding that there is a large change in mechanical properties of parchment at the $\mathrm{RH}$ lower than $25 \%$, the recommended storage conditions suggest the $\mathrm{RH}$ between 30 and $40 \%$ ( $+/-5 \%$ fluctuation) [9]. Other suggestions assume the humidity of $40-50 \% \mathrm{RH}$ or even higher [11, 35]. Based on these literature outcomes, we have decided to subject our samples to the $\mathrm{RH}$ changes ranging from 20 to $80 \%$, with $50 \%$ taken as the reference $\mathrm{RH}$. Both samples $\left(S_{u}\right.$ and $\left.S_{m}\right)$ were placed for a period of 9 days in the climatic chamber at a constant temperature of $20{ }^{\circ} \mathrm{C}$ and relative humidity varying according to the designed scenario. The intended and set at the climatic chamber controller RH scenario was 50-35-20-50-65-80-50[\%]. The predesigned $\mathrm{RH}$ values were additionally controlled inside the chamber with the EH (located as shown in Fig. 5) and their real step values at the parchment plane equal to 54-41-39-54-67-80-54[\%]. Note that the intended maximum decrease of $\mathrm{RH}$ was $20 \%$, but due to the climatic chamber limitations, finally, it reached $39 \%$ only. Also, the real reference $\mathrm{RH}$ value was equal to $54 \%$. The total experiment lasted $216 \mathrm{~h}$. During the first and last $48 \mathrm{~h}$ the samples were conditioned at 54\% RH (ISO 2419:2012) and next the sequential $\mathrm{RH}$ changes were performed each $24 \mathrm{~h}$.

The RH scenario after the initial conditioning was divided into 6 phases, which are indicated in Fig. $6 \mathrm{a}$ and which are summarized in Table 1.

Phases 4-6 represent the rehydration process, i.e., absorption of water, which may result in expansion across all dimensions. Please note that the RH changes in the function of time (Fig. 6a) are presented schematically as the quasi step-like $\mathrm{RH}$ variations. This is due to the time scale, which is given in hours. However, the actual speed of $\mathrm{RH}$ changes is approximately $1 \%$ per minute, as measured experimentally. The example, measured function $\mathrm{RH}(\mathrm{t})$ for $\mathrm{S}_{\mathrm{u}}$ and $\mathrm{S}_{\mathrm{m}}$ occurring for the $\mathrm{RH}$ step $80 \%-54 \%$ is shown in Fig. 6b. These plots show that the $\mathrm{RH}$ value for the highest $\mathrm{RH}$ change applied during the experiment stabilises after approx. $45 \mathrm{~min}-60 \mathrm{~min}$. Also, by comparing the transient $\mathrm{RH}(\mathrm{t})$ plots measured for $\mathrm{S}_{\mathrm{u}}$ and $\mathrm{S}_{\mathrm{m}}$ at the beginning of Phase 6 (blue and orange line in Fig. 6b), the good repeatability of the $\mathrm{RH}$ changes process is confirmed. On the other hand, this observation indicated the need for monitoring the samples in two alternative data 


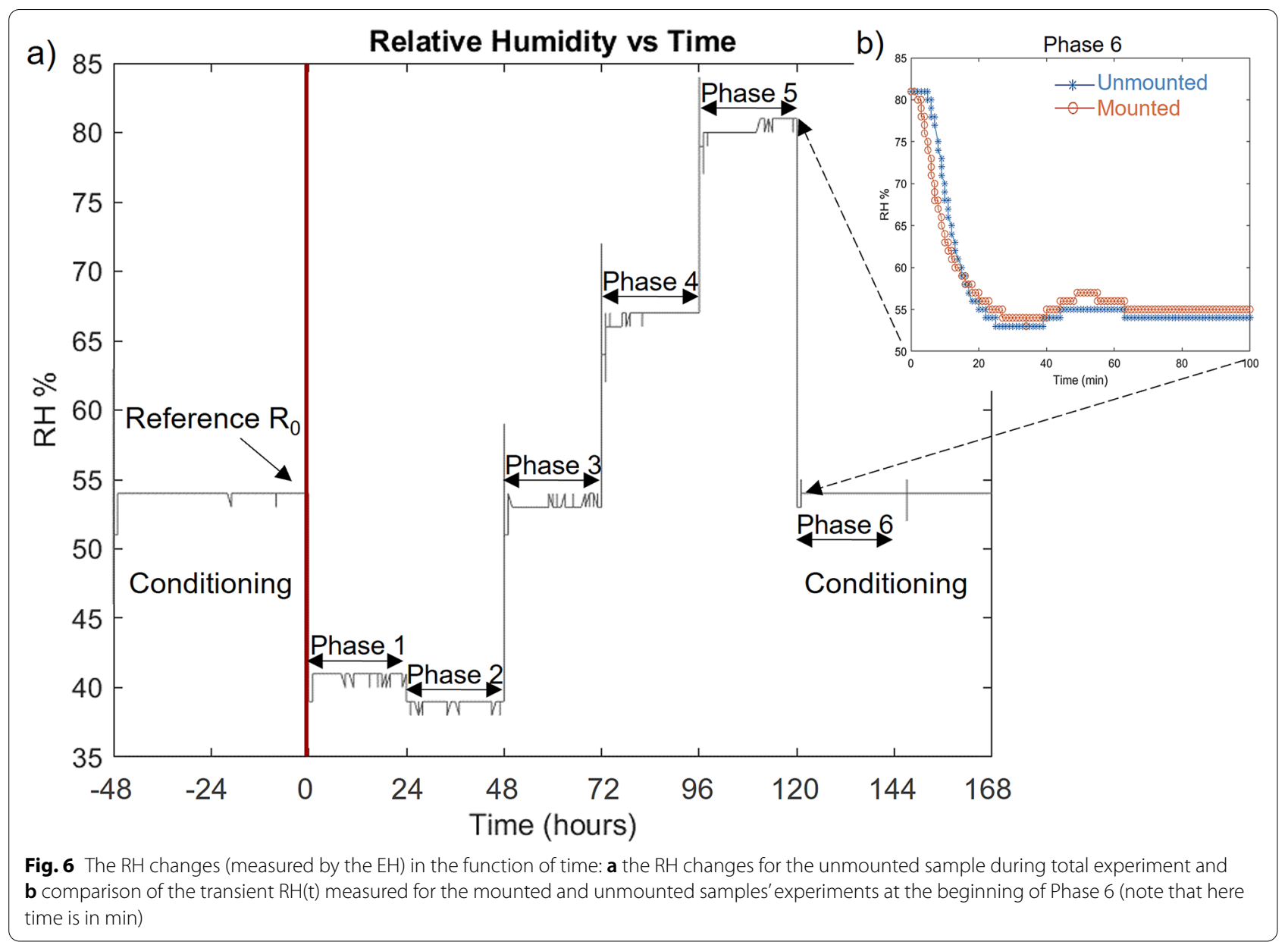

Table 1 Relative humidity scenario

\begin{tabular}{lll}
\hline & Duration (hours) & RH scenario \\
\hline Conditioning & 48 & Decrease from environmental to $\mathbf{5 4 \%}$ and stabilization \\
Phase 1 & 24 & Decrease from $\mathbf{5 4}$ to $\mathbf{4 1 \%}$ and stabilization \\
Phase 2 & 24 & Decrease from $\mathbf{4 1}$ to $\mathbf{3 9 \%}$ and stabilization \\
Phase 3 & 24 & Increase from $\mathbf{3 9}$ to $\mathbf{5 4 \%}$ and stabilization \\
Phase 4 & 24 & Increase from $\mathbf{5 4}$ to $\mathbf{6 7 \%}$ and stabilization \\
Phase 5 & 24 & Increase from $\mathbf{6 7}$ to $\mathbf{8 0} \%$ and stabilization \\
Phase 6 & 24 & Decrease from $\mathbf{8 0}$ to $\mathbf{5 4 \%}$ and stabilization \\
Conditioning & 48 & Stabilization at $\mathbf{5 4 \%}$ (including Phase 6$)$ \\
\hline
\end{tabular}

recording modes: fast and slow frames capture. The fast recording with frequency of 4 captures per minute starts $10 \mathrm{~min}$. before the beginning of each $\mathrm{RH}$ change, and it lasts approximately two hours. The slow recording (4 captures per hour) is carried during all remaining time, i.e. approx. $22 \mathrm{~h}$ during each stabilization period. Implementation of these two capturing modes allows us to reduce the amount of data without the risk of losing important information during transient events. Even with this reduced capture scenario, during monitoring one sample $\left(S_{u}\right.$ or $\left.S_{m}\right)$, we grabbed more than 3500 pairs of images resulting in approx. $40 \mathrm{~GB}$ of raw data from both measurements.

As explained in the section devoted to DIC, the method requires selecting the reference pair of frames for further displacements analysis during the experiment. The 
reference pair of frames corresponds to the time moment which we assume as the initial for the performed analysis. In our studies, the selected reference $\mathrm{R}_{0}$ (as shown in Fig. 6a) was captured at the end of the parchments conditioning period $\left(48 \mathrm{~h}\right.$ in $54 \%$ humidity at $20^{\circ} \mathrm{C}$ ). All displacements and strain maps presented in this paper are calculated using $R_{0}$ as the reference, i.e. all displacement values represent the difference in position between $R_{0}$ and the actual one.

The FoVs captured during the experiments were the same for $S_{u}$ and $S_{m}$. They were sufficiently large to cover the total area of each sample, and additionally, in the case of $\mathrm{S}_{\mathrm{m}}$ FoV included partly the elastic stripes covered with artificial texture (see Fig. 5c). This allows not only to monitor the shape and displacements of the samples but also enables approximate analysis of the parchment mount response to $S_{m}$ deformations. Each pair of data was processed referring to the reference one, and the actual shape and the set of $(\mathrm{U}, \mathrm{V}, \mathrm{W})$ displacements were calculated. The two sets of results for $S_{u}$ and $S_{m}$ respectively are further analysed according to the following scenario:

- The analysis of in-plane (U) and out-of-plane displacements (W) of a pair of horizontal elastic strips from the opposite side of parchment (as indicated in Fig. 5c) performed at the end of stabilisation of each of the Phases 1-6. As the FoV does not include the pair of vertical hinges, we did not comment on the behaviour of the mount in this direction.

- The investigations of full-field distributions, the scale and spatio-temporal distribution of out-of-plane (W) displacements during $\mathrm{RH}$ changes between the sequential phases (1-6) and after their stabilization. The shape and W-displacement maps were compared for the end of each stabilization phase, while the full spatio-temporal analysis of out-of-plane displacements was performed for the selected cross sections of $\mathrm{S}_{\mathrm{u}}$ and $\mathrm{S}_{\mathrm{m}}$.
- The analysis of the full-field distributions, the scale and spatio-temporal distributions of in-plane displacements $(\mathrm{U}, \mathrm{V})$ and strains $\left(\varepsilon_{\mathrm{xx}}, \varepsilon_{\mathrm{yy}}, \varepsilon_{\mathrm{xy}}\right)$ during $\mathrm{RH}$ changes between the sequential phases (1-6) and after their stabilization.

- The global analysis of the efficiency of the mount (in terms of minimising parchment deformations and strains) through the comparison of Peak-to-Valley $(\mathrm{P} / \mathrm{V})$ values of the displacements $(\mathrm{U}, \mathrm{V}, \mathrm{W})$ and strains $\left(\varepsilon_{x x}, \varepsilon_{y y}, \varepsilon_{x y}\right)$ of $S_{u}$ and $S_{m}$ in the function of time (168 h).

\section{Results and discussion}

\section{Analysis of the mount performance}

The main task of the mount is to minimize the out-ofplane displacements (W) of the parchment. Therefore, it is expected that also W-displacements of the elastic strips will be small despite to the RH changes. Figure 7 presents the colormap of out-of-plane displacements as measured at the end of each Phase 1-6 for the example of 3 strips: a pair of horizontal ones and one vertical (Fig. 5c). The strips' values of W-displacement are for the given phase very similar and small. Nevertheless, a slow and linear change is detected, which is expected as the ESs are bind to the support system (zero movement). The maximum W-displacement of ES $(0.6 \mathrm{~mm})$ is reached for Phase 5 , while the minimum value (ap. $0.2 \mathrm{~mm}$ ) - for Phase 1 .

Figure 8 represents U- displacements of the ES corresponding to the Phases $1-6$. Their values represent in-plane rigid body motion in $\mathrm{x}$-direction. The upper strip's U-displacement is close to zero for all phases i.e. that the $y$-component of $U$-displacement is very weak. The U-values for right and left ES in the horizontal pair are different and the $\mathrm{P} / \mathrm{V}$ of these values indicates the local influence of the mount on the parchment. The $\mathrm{P} / \mathrm{V}$ values are highest $(1.28 \mathrm{~mm})$ for the Phase 5 and lowest $(0.11 \mathrm{~mm}$ and $0.20 \mathrm{~mm})$ for Phases 3 and 6 , respectively. The U-displacement values indicate compression in the

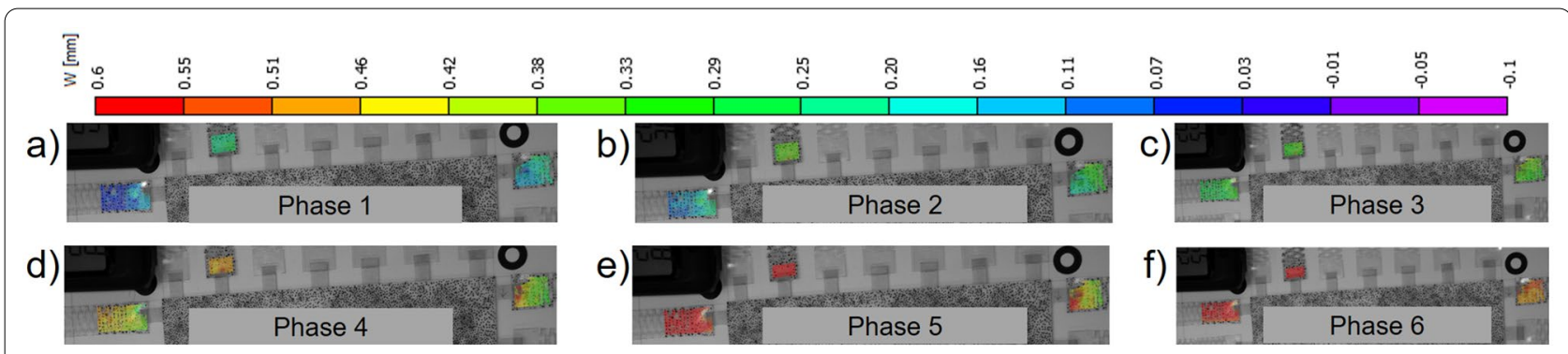

Fig. 7 2D W-displacement colourmaps of the elastic strips of the mounting system corresponding to the RH Phases $1-6$ 


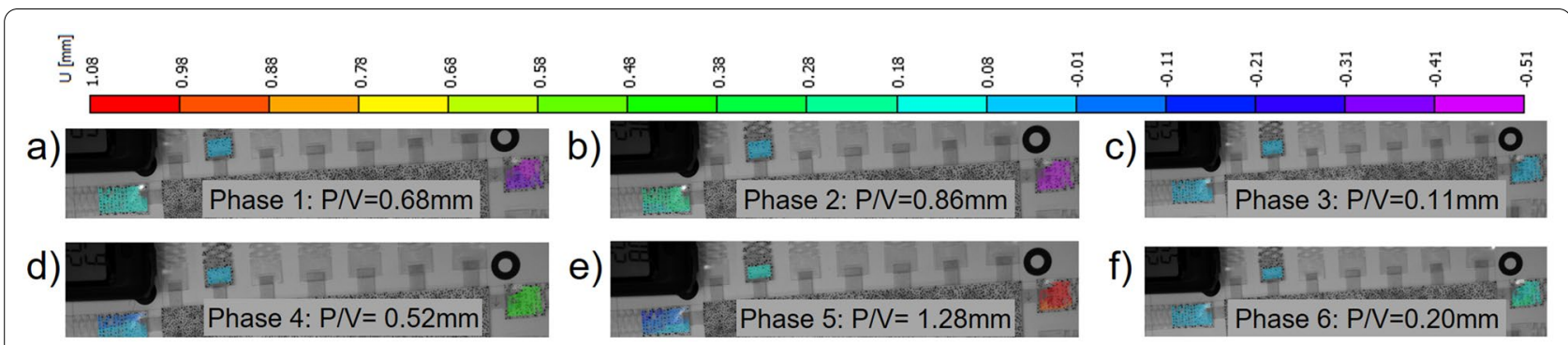

Fig. 8 2D U-displacement colormaps of the hinges of the mounting system corresponding to RH phases 1-6. For each case the peak-to-valley value (P/N) of $\mathrm{U}$-displacements is also shown

x-direction for Phases 1, 2, and 6, while low and strong expansion for Phases 4 and 5, respectively, while the $\mathrm{y}$-component of $\mathrm{U}$-displacement is very weak.

These initial observations indicate that the mount works in general as expected, namely the out-of-plane displacements of ES are small through all RH changes, while in-plane displacements change significantly among different $\mathrm{RH}$ phases responding vividly to the parchment deformations due to RH changes. In the next sections we will investigate in details how it translates to capability to mitigate the parchment deformations.

\section{Monitoring of 3D shape and out-of-plane displacements}

The first important aspect of the parchment analysis is to study the out of plane displacements of the samples at different RH phases. The W displacements are the most

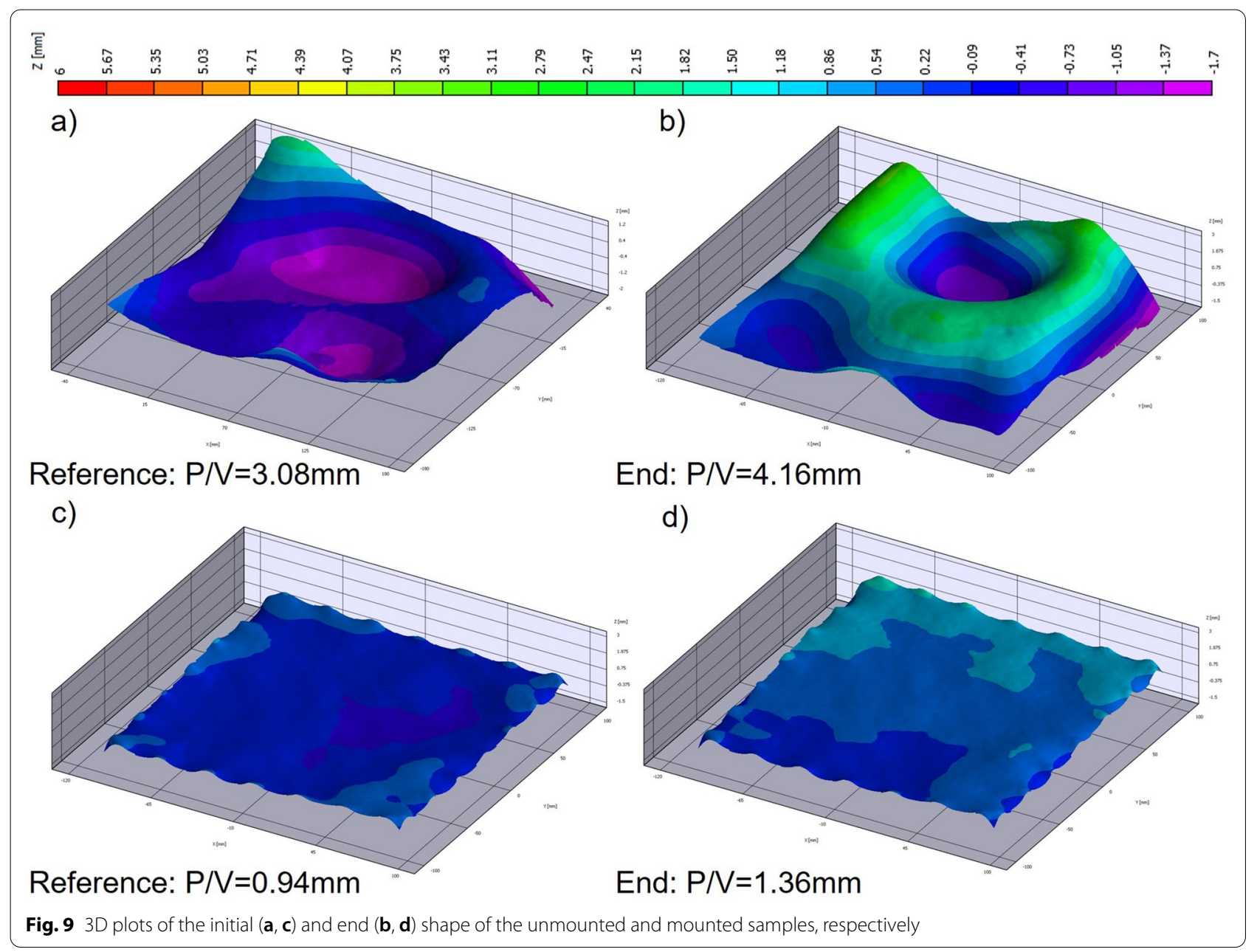


visible change of parchment exposed to changing $\mathrm{RH}$. We start with the presentation of the 3D plots of initial (reference) and end shapes of $S_{u}$ and $S_{m}$ (Fig. 9). The measurements were performed after the samples conditioning, i.e. the reference shape-after the first $48 \mathrm{~h}$ of the experiment and final shape - after the last $48 \mathrm{~h}$ (according to Fig. 6). As shown in Fig. 9a, b, the unmounted sample is initially significantly deformed $(\mathrm{P} / \mathrm{V}=3.08 \mathrm{~mm})$, and its shape had changed considerably after the experiment $(\mathrm{P} / \mathrm{V}=4.16 \mathrm{~mm})$, although the initial and final levels of the relative humidity were the same. The mounted sample was initially relatively flat $(\mathrm{P} / \mathrm{V}=0.94 \mathrm{~mm})$, and after the experiment, its final shape had not changed significantly $(\mathrm{P} / \mathrm{V}=1.36 \mathrm{~mm})$, as shown in Fig. $9 \mathrm{c}, \mathrm{d}$. However, the mounts have caused local, small modulations of the shape at the sample edges with the value $\mathrm{P} / \mathrm{V}$ approx. $0.13 \mathrm{~mm}$.

To analyze in more detail the samples' responses for the RH scenario, we compared the shapes and out-of-plane displacements of $S_{u}$ and $S_{m}$ at the end of Phases 1-6. The W-displacements in Figs. 10 and 11 are presented as colourmaps superimposed on the 3D plots of actual shapes of the unmounted and mounted samples. Comparing the results for $S_{u}$ and $S_{m}$ it is clearly seen that the shape and out-of-plane displacements in $S_{m}$ reach smaller $\mathrm{P} / \mathrm{V}$ values and smaller gradients than in $S_{u}$. This confirms that the parchment mount significantly reduces out-of-plane displacements and stabilizes their values. The $\mathrm{P} / \mathrm{V}$ of W-displacements for $\mathrm{S}_{\mathrm{m}}$ varies from 0.76 to $2.11 \mathrm{~mm}$ over the whole range of $\mathrm{RH}$ changes, while the $\mathrm{P} / \mathrm{V}$ of $\mathrm{W}$ for $\mathrm{S}_{\mathrm{u}}$ varies from 0.92 up to $6.96 \mathrm{~mm}$. The minimum displacement values for $S_{u}$ and $S_{m}$ were recorded in Phase 3, and they equal 0.92 and $0.76 \mathrm{~mm}$ respectively. The most significant impact on both $\mathrm{S}_{\mathrm{u}}$ and $\mathrm{S}_{\mathrm{m}}$ samples occurred in Phase 5, for which the highest displacement values are recorded $\left(\mathrm{S}_{\mathrm{u}}: 6.96 \mathrm{~mm}\right.$ and $\left.\mathrm{S}_{\mathrm{m}}: 2.11 \mathrm{~mm}\right)$. The mount influences also the character of the displacements: for $S_{u}$ the displacements change from concave through nearly flat (Phase 3) to convex (Fig. 10), while for $S_{m}$-the convex-like displacement at Phase 1 changes for convex at Phase 3 and finally it stabilizes with the quasi-convex displacement distribution by the end of the stabilisation at Phase 6 (Fig. 11).

Additionally, analyzing the displacements at the edges of $S_{m}$ we notice that the elastic strips do not cause significant local W-displacements at any of the phases. (Fig. 11). This observation confirms that ES and joints are correctly done and that they have a stable performance during $\mathrm{RH}$ changes.

The results presented in Figs. 10 and 11 allow us to compare the shapes and out-of-displacements of $\mathrm{S}_{\mathrm{u}}$ and $S_{m}$ at the selected time moments; however, they do not present the full temporal behaviour of the samples. Of course, we have access to the data in the form of a

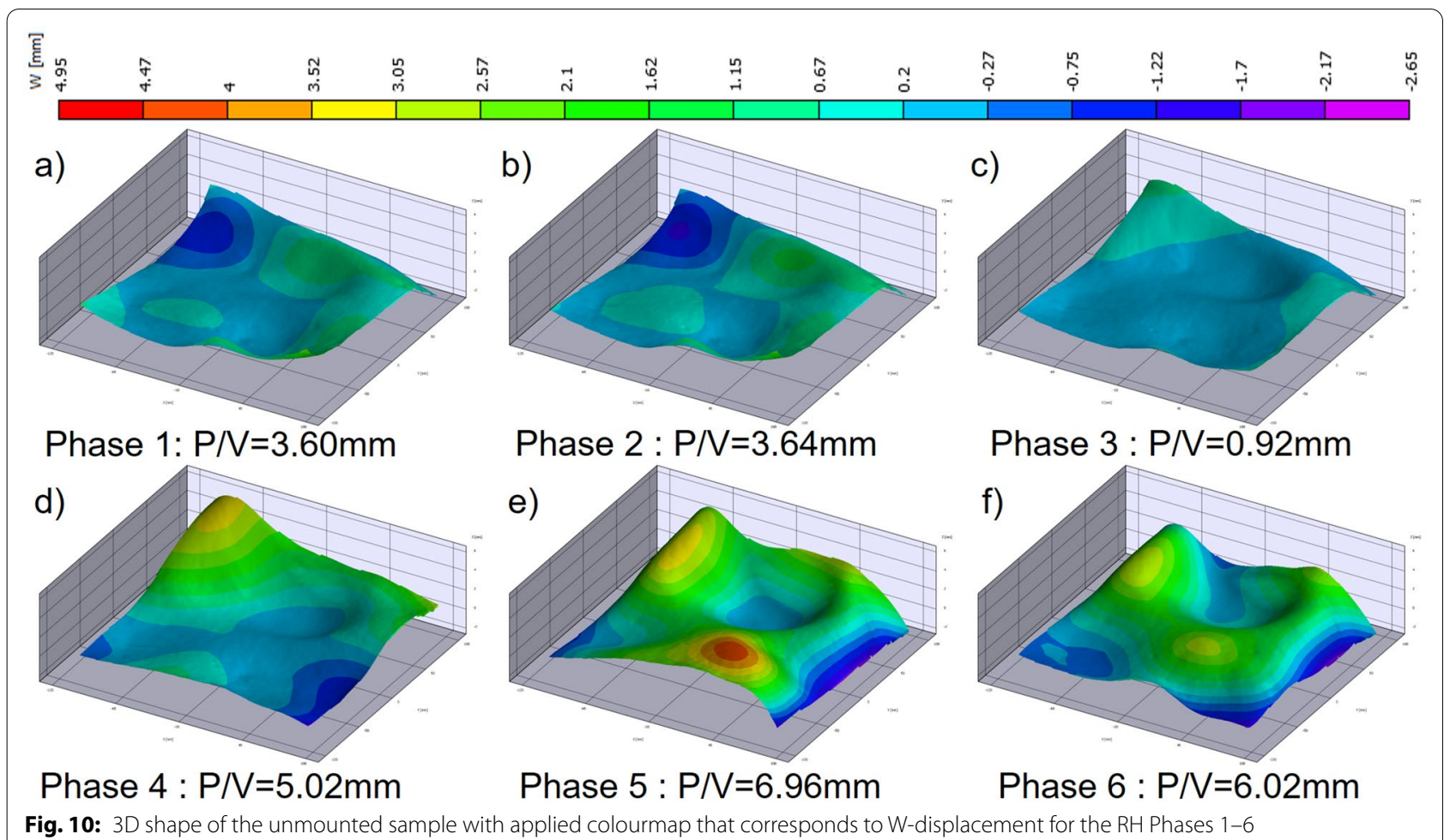

Fig. 10: 3D shape of the unmounted sample with applied colourmap that corresponds to W-displacement for the RH Phases 1-6 


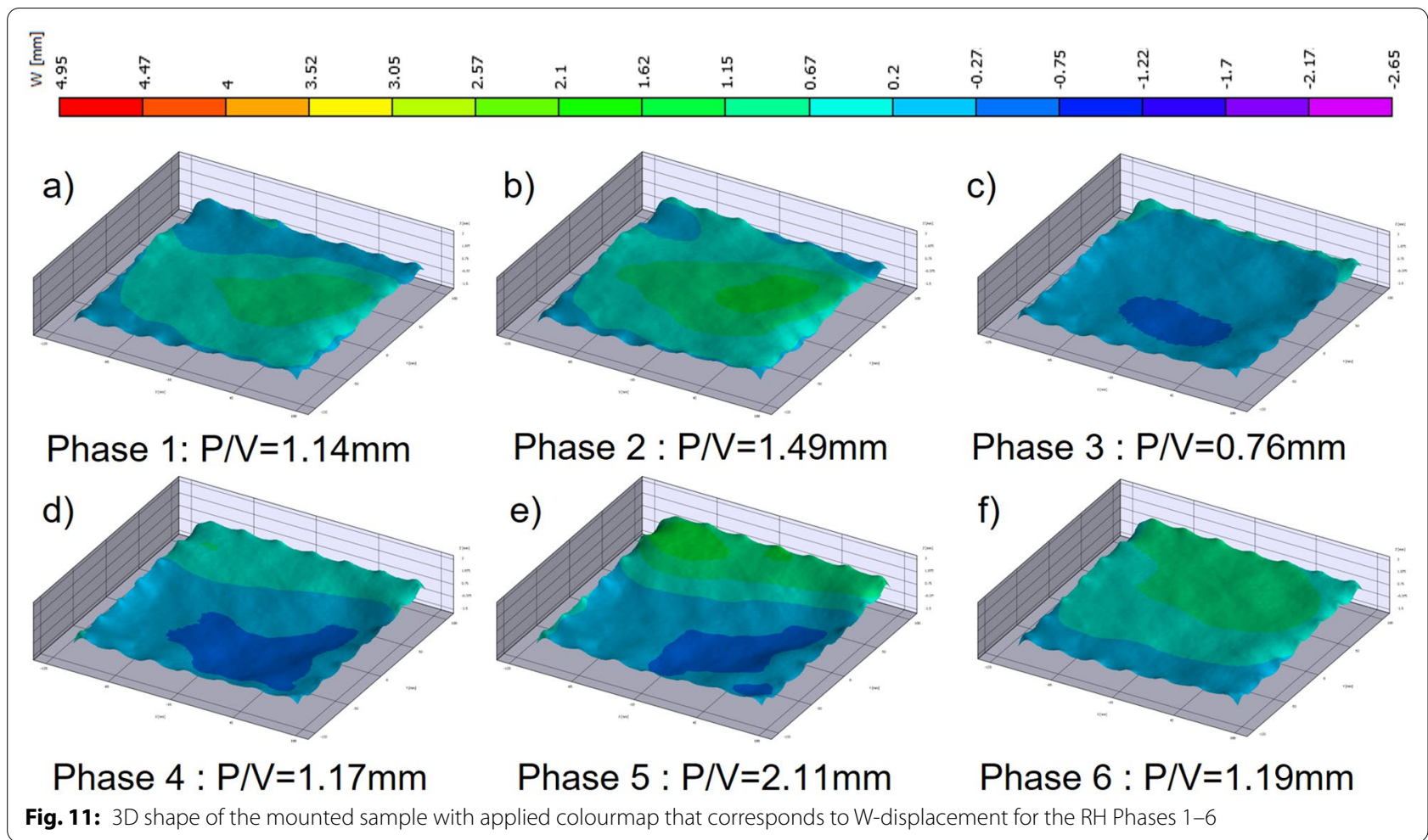

4D file containing $\mathrm{W}(\mathrm{x}, \mathrm{y} ; \mathrm{t})$ from full measurements, but it is not convenient for visualisation purposes. Instead, we propose to create a spatio-temporal map composed of the $\mathrm{W}$-values along the selected horizontal cross section $\mathrm{L}_{0}$ (as shown in Fig. 2 for $\mathrm{L}_{\mathrm{Sm}}$ and $\left.\mathrm{L}_{\mathrm{Su}}\right)$ in the function of time. The cross sections were located $20 \mathrm{~mm}$ from the edge of the sample. They were selected so that they include the thickness variations in both samples $\left(\mathrm{S}_{\mathrm{u}}: 0.395-0.530[\mathrm{~mm}]\right.$ and $\mathrm{S}_{\mathrm{m}}: 0.430-$ $0.510[\mathrm{~mm}])$, which can reveal differences in the behaviour of the material. The first spatio-temporal maps of the cross sections (Figs. 12a and 13a) represent changes in W-displacements during the experiment $(168 \mathrm{~h})$. The displacement colour scale for these maps is kept the
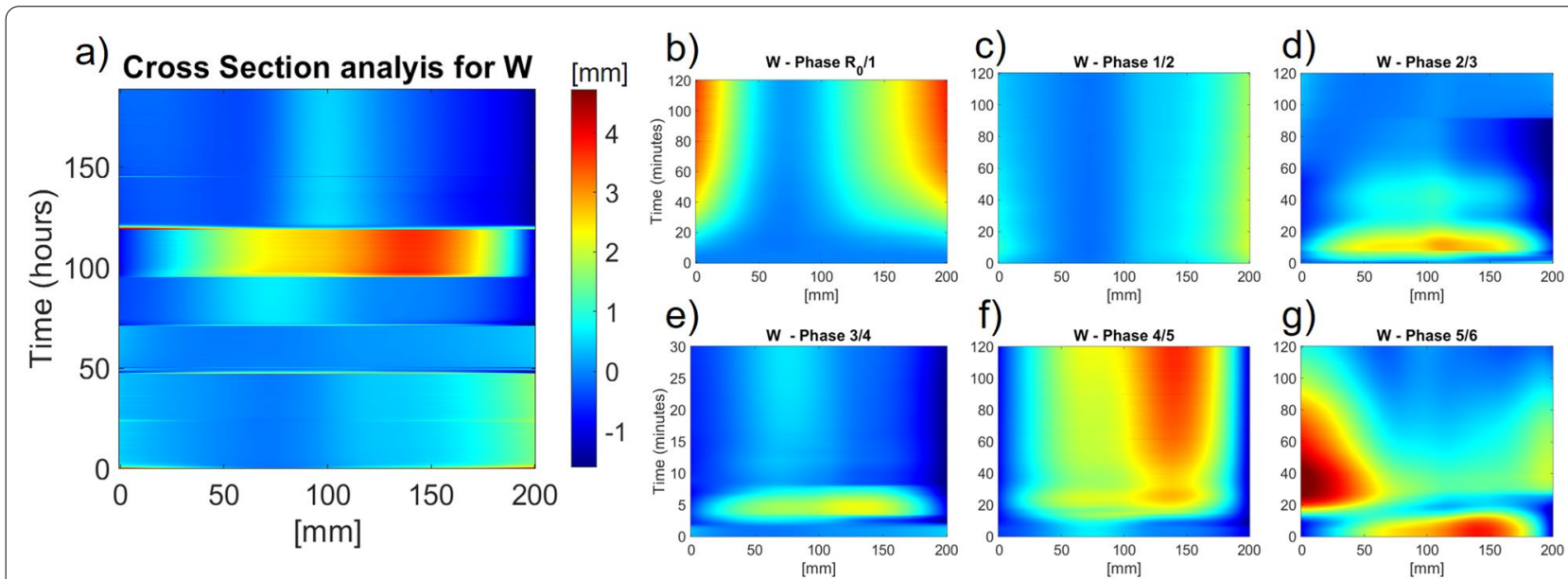

Fig. 12 The spatio-temporal maps of $W$-displacement in the crossection $L_{0}$ of the unmounted sample. The maps $W(x, t)$ representing a the experiment duration $\mathbf{b}$-e detailed maps $W(x, t)$ for the rapid $\mathrm{RH}$ changes between sequential Phases $\mathrm{R}_{0}-6$ for the time span of 120 min (the colour scale for all maps is the same) 


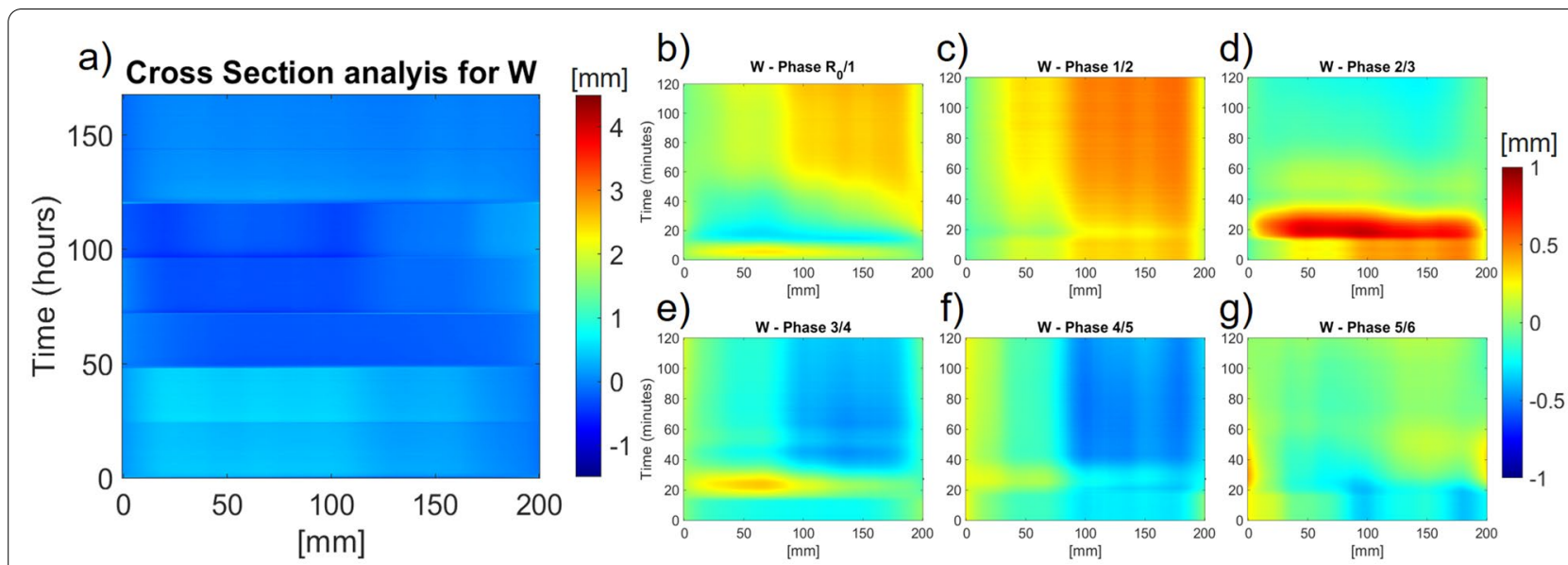

Fig. 13 The spatio-temporal maps of $W$-displacement in the crossection $L_{0}$ of the mounted sample. The maps $W(x, t)$ representing a the whole experiment duration (the scale the same as in Fig. 12) b-e) detailed maps $W(x, t)$ for the rapid RH changes between sequential Phases $R_{0}-6$ for the time span of 120 min (the scale $3 \times$ smaller than in Fig. 12)

same, and therefore, we can easily conclude that the displacements in the selected cross section of $\mathrm{S}_{\mathrm{m}}$ are at least three times smaller than those of $\mathrm{S}_{\mathrm{u}}$. The following maps (Figs. $12 \mathrm{~b}-\mathrm{e}$ and $13 \mathrm{~b}-\mathrm{e}$ ) represent 2 -h time spans. These maps give a glimpse to the full evolution of the displacements during $\mathrm{RH}$ changes between the sequential RH levels. In order to analyse these displacements in detail the unified colour map scale for $S_{m}$ is three times smaller than for $S_{u}$.

The most significant W-displacements in $\mathrm{L}_{0}$ of $\mathrm{S}_{\mathrm{u}}$ occur during Phase 5 (Fig. 12a) and during RH changes from 67 to 80\% (Fig. 12g). Also, the RH transition from Reference $\left(R_{0}\right)$ to Phase 1 and from Phase 4 to Phase 5 are also inducing high displacements that are not suppressed within $2 \mathrm{~h}$ (Fig. 12b and f). On the contrary, the displacements generated during the $\mathrm{RH}$ transition of the remaining Phases 3-4 (Fig. 12c-e), are released fast, allowing the sample to return close to its original shape. It should be noted that, although the RH steps between Phases 3/4 and Phases $4 / 5$ are equal (13\% difference), the distribution of transient displacements (Fig. 12e and f) are significantly different. This is in agreement with the literature reports $[6,35,55]$, which may indicate denaturation and gelatinisation processes occurring when $\mathrm{RH}$ reach high values (here $80 \%$ ).

As mentioned before and shown in Fig. 13a, the W-displacements at $\mathrm{L}_{\mathrm{Sm}}$ are much smaller (when compared with $\mathrm{L}_{\mathrm{Su}}$ ) during all phases, including the Phase 5 . The displacement evolution during transitions between all phases is completed fast, and the sample stabilises quickly (aprox. after $30 \mathrm{~min}$ ) and the range of the W-displacement values during $\mathrm{RH}$ transition is small (less than $1 \mathrm{~mm})$. The spatial distribution of W-displacement along
$\mathrm{L}_{\mathrm{Sm}}$ indicates periodic modulation of its values with the maximum amplitude equal approx. $0.15 \mathrm{~mm}$. This spatial modulation, with variable amplitude (Fig. 13b and c) is caused by the presence of hinges and elastic springs.

We had also analysed W-displacement maps in reference to the $S_{u}$ and $S_{m}$ thickness variations along $L_{0}$. As shown in Fig. $2 \mathrm{a} \mathrm{S}_{\mathrm{u}}$ has the smallest thickness $(0.39 \mathrm{~mm})$ at the middle of the cross section, while it is thickest at the left edge $(0.48 \mathrm{~mm})$. The direction of the fibres changes significantly at the middle of the cross section. The thickness variations of $\mathrm{S}_{\mathrm{m}}$ are smaller with an average thickness equal to $0.42 \mathrm{~mm}$ ) and the local peaks of thickness occurring at the middle $(0.47 \mathrm{~mm})$ and at the left edge $(0.465 \mathrm{~mm})$ of $\mathrm{S}_{\mathrm{m}}$. The average direction of fibres is 45 deg. Due to multiple physical effects occurring in the parchment material during dehydration and rehydration processes, it is tough to predict the influence of thickness material on the W-displacement. However, for $S_{u}$ we notice significantly different behaviour of the sample at the middle of $\mathrm{L}_{\mathrm{Su}}$ : the displacement has there an inflection point for phases 1-5 while for Phase 6, a local extremum of displacement occurs in the middle of the cross section, (Fig. 12a). Such character of $\mathrm{S}_{\mathrm{u}} \mathrm{W}$-displacement changes is confirmed also in the transition maps (Fig. 12b-g) and can be caused by the local small thickness of the parchment combined with the local direction of the fibres. For $\mathrm{S}_{\mathrm{m}}$ such correspondence between the local thickness variations and W-displacements cannot be noticed.

In overall, the mounted sample has much lower out-of-plane displacements in comparison to the unmounted one (Figs. 12 and 13) at the selected cross 
section. Also, its W-displacements stabilises much quicker after the RH changes.

\section{Monitoring of in-plane displacements and strains}

The second aspect of our analysis is the monitoring of full-field in-plane ( $U$ and $V$ ) displacements of $S_{u}$ and $\mathrm{S}_{\mathrm{m}}$ during their exposure to varying $\mathrm{RH}$. The in-plane displacements and strains corresponding to the end of the different humidity phases are presented as colormaps superimposed on the 2D images of the samples for Phases 1-6 (Figs. 14, 15, 16, 17, 18 and 19). The P/V values of $U$ - and V-displacements for $S_{u}$ and $S_{m}$ are at a similar range (from 0.1 to $2.1 \mathrm{~mm}$ ) with slightly lower values for the mounted sample. The minimum $P / V$ values of $U$ and V-displacements for $S_{u}$ and $S_{m}$ are reached at Phase 3 and maximum $\mathrm{P} / \mathrm{V}$ values at Phase 5 .

In order to better understand the changes in the inplane displacement distributions, the results are correlated with the directionality of the samples' fibre (shown in Fig. 2). For both, $S_{u}$ and $S_{m}$, the major fibre direction is diagonal to the samples with bigger direction variations present in $S_{u}$. In $S_{u}$, the displacements' variations in the sample are directly connected with the fibre directions. If the sample has a constant thickness and 45 deg of fibres orientation, then linear and equal displacements in both $\mathrm{x}$ and $\mathrm{y}$ directions are expected. In Figs. 14 and 15 we observe strong linear terms in both U- and V-displacements, however the displacements are locally modified due to the change of the direction of the fibres as indicated in Fig. 2a. This is well illustrated in Fig. 15, where nonlinear changes are clearly seen at the bottom of V-displacement maps. This is the location where the direction of fibres is changing locally from diagonal to horizontal. This effect is most probably additionally enhanced by a reduced thickness of the sample in this location. Comparing the $\mathrm{U}$ - and V-displacements maps in $\mathrm{S}_{\mathrm{u}}$, we observe the change of their inclination and their rotation, which indicates differences in stretching and shrinking of the sample material between different RH Phases. The biggest difference in both $\mathrm{U}$ - and V-displacements occurs between the Phases 5 and 6 i.e. returning to reference $\mathrm{RH}$ after rehydration process. The smallest values of both inplane displacements occur in Phase 3 (return to 54\% RH after dehydration process), which is also correlated with the minimum W-displacement. It should be noted that the sample's displacements are still significant at the end of Phase 6 i.e. after final stabilization at $\mathrm{RH}=54 \%$.

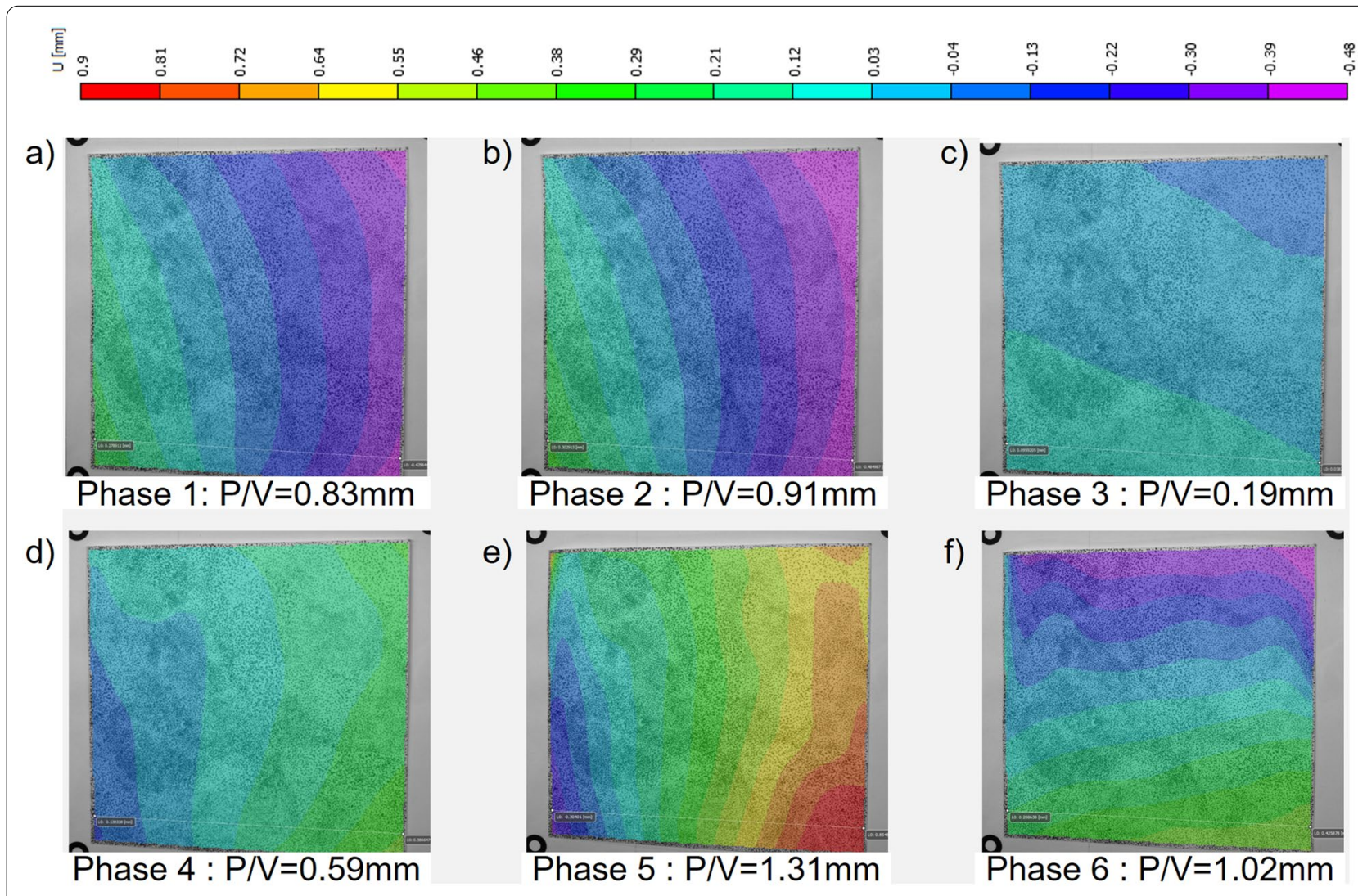

Fig. 14: $2 D$ colormap of the $U(x, y)$ in-plane displacement of the unmounted sample at the end of Phases 1-6 


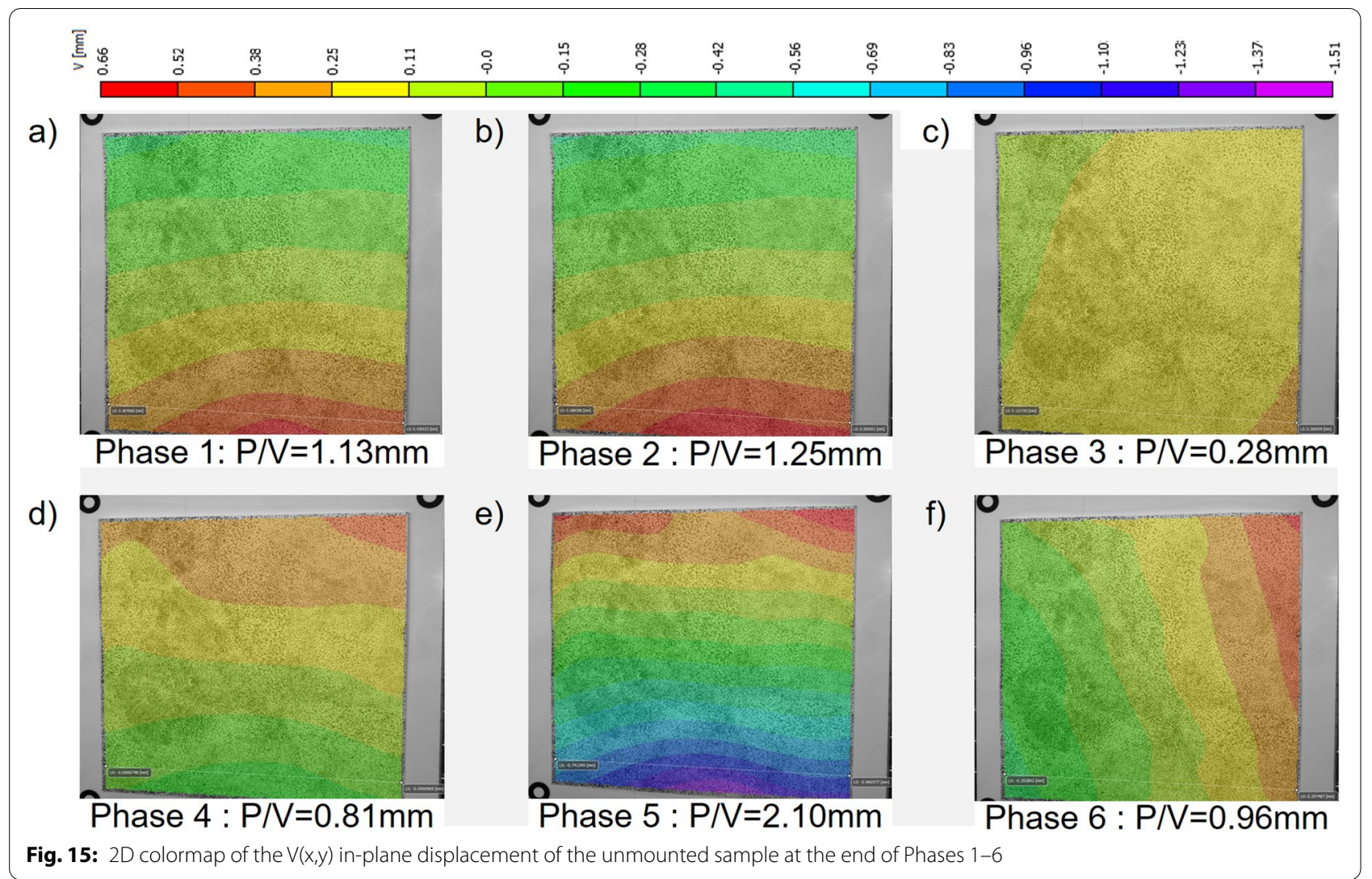

The strains, simply speaking, are calculated as the first derivatives of displacement fields with respect to $\mathrm{x}\left(\varepsilon_{\mathrm{xx}}\right.$ for U-displacement) and to $\mathrm{y}\left(\varepsilon_{\mathrm{yy}}\right.$ for $\mathrm{V}$-displacement), while shear strain $\varepsilon_{x y}$ is given by the sum of the cross derivatives of both in-plane displacements. Due to different values of the linear terms in displacements reached at the sequential Phases, we expect different levels of $\varepsilon_{\mathrm{xx}}$ and $\varepsilon_{\mathrm{yy}}$ strains generated for each of the Phases. The example strain maps $\varepsilon_{x x}, \varepsilon_{y y}$ and $\varepsilon_{x y}$ of $S_{u}$ calculated for Phases 1, 5, and 6, are presented in Fig. 16. These phases were selected as their $\mathrm{U}$ - and V-displacements vary significantly in the inclination and direction. The strains $\varepsilon_{\mathrm{xx}}$ and $\varepsilon_{\mathrm{yy}}$ for Phase 1 have negative values, which indicate compression/contraction, while for Phase 5-positive values i.e. stretching/expansion of the sample. The $\varepsilon_{\mathrm{yy}}$ strains have bigger values and variations for Phases 1 and 5 when compared with $\varepsilon_{\mathrm{xx}}$.

The $\varepsilon_{\mathrm{xx}}$ and $\varepsilon_{\mathrm{yy}}$ strain values for Phase 6 have positive values close to zero. The biggest variations of $\varepsilon_{x x}$ are observed at the upper parts of the left and right edges of $\mathrm{S}_{\mathrm{u}}$ (Fig. 16a, d, and g), which is due to the local gradients of U-displacements caused perhaps by differences in the local thickness of the sample or a very local sample damage at the edge. The biggest variations of $\varepsilon_{\mathrm{yy}}$ are localised at the middle of the bottom of the sample (Fig. 16b and e) and it is correlated with local small thickness and the change of the fibres directions towards parallel to $\mathrm{x}$-axis (Fig. 2a). The shear strain $\varepsilon_{x y}$ for all Phases have values close to zero, with the biggest variations for Phase 5 (Fig. 16f).

While studying the in-plane displacement maps of the mounted sample (Figs. 17a-f and 18a-f), we observe their similar, in general, character as in the case of $S_{u}$, except for the end of Phase 6 at which the gradients of displacements (Figs. $17 \mathrm{~g}$ and $18 \mathrm{~g}$ ) are much smaller than those of $\mathrm{S}_{\mathrm{u}}$. The $\mathrm{P} / \mathrm{V}$ of $\mathrm{U}$ - and V-displacements for Phases 3 and 6 reach very small values which means that they are not stretched or compressed comparing with initial conditions $\left(\mathrm{R}_{0}\right)$. The $\mathrm{U}$ - and V-displacements at Phases 1,2 and 5,6 have strong linear terms in consequence they generate reasonably uniform strain maps in total FoV (Fig. 19). The $\varepsilon_{\mathrm{xx}}$ and $\varepsilon_{\mathrm{yy}}$ strains are similarly as for $S_{u}$, compressive for Phase 1, stretching for Phase 5 and slightly stretching for Phase 6 (Fig. 19). The biggest variations of strains present at the bottom of $\varepsilon_{y y}$ map in Phase 5 (Fig. 19e) may be connected with the variations in thickness and changing directionality of fibres (tilting towards $\mathrm{x}$ axis) in $\mathrm{S}_{\mathrm{m}}$. The shear strain maps have slightly positive values for Phases 1 and 5 and nearly zero values for Phase 6. 


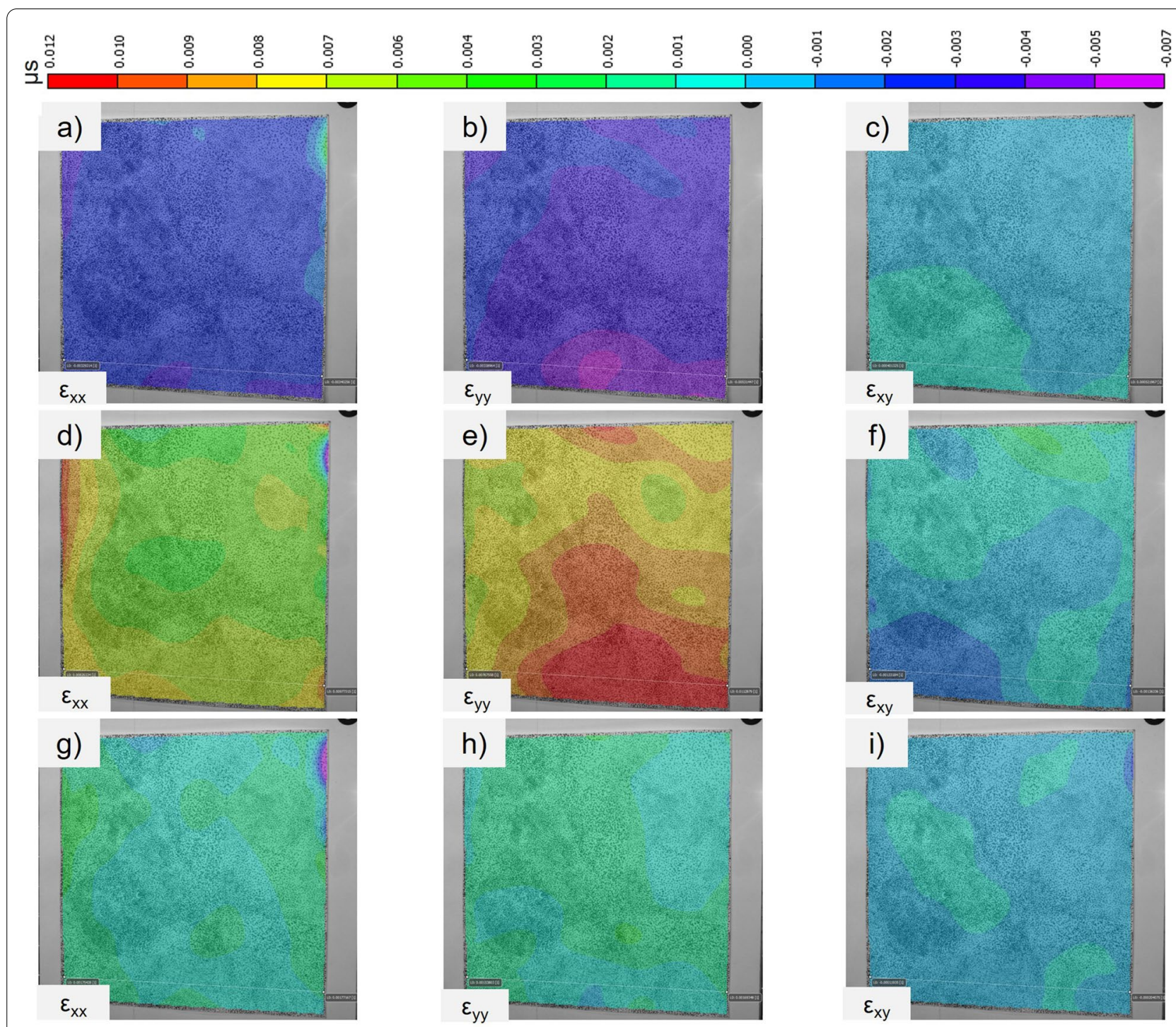

Fig. 16 The strain maps $\varepsilon_{x x^{\prime}} \varepsilon_{y y}$ and $\varepsilon_{x y}$ of the unmounted sample calculated for Phase $1(\mathbf{a}-\mathbf{c}$, Phase 5 (d-f) and Phase 6 (g-i), respectively

The displacement and strain maps presented in Figs. 14, 15, 16, 17, 18 and 19 provide full-field information about these measurands at the end of Phases 1-6 only. However, it is also important to study in details and compare the spatio-temporal moisture-related strain in $S_{u}$ and $S_{m}$ samples during the experiments. As mentioned in the previous section it is difficult to illustrate this for full FoV and therefore the maps of strains at the crossection $\mathrm{L}_{0}$ (Fig. 2) in the function of time with temporal sampling 4 captures/hour $(168 \mathrm{~h})$ are presented in Figs. 20 and 21. The spatio-temporal maps of strains for $S_{u}$ and $S_{m}$ are colour coded using the same scale for both samples. The maps clearly indicate strong dependence of strains values from the $\mathrm{RH}$ levels. They also show that the values after each $\mathrm{RH}$ step change significantly and they are not released or notably changed during stabilisation periods.

The strains $\varepsilon_{\mathrm{xx}}$ and $\varepsilon_{\mathrm{yy}}$ to which is subjected the mounted sample (in $\mathrm{L}_{0}$ ) have approx. 2-3 times lower values than the unmounted one, however the character of the changes is similar i.e. compression/contraction for Phases 1-3 and strong stretching/expansion for Phase 5. Both samples at this crossection undergo small (but with different value for each Phase) shear strain. At the other hand, the $\varepsilon_{y y}$ strain map of the unmounted sample includes the visible extrema located at the middle of crossection (Fig. 20b), which confirms the influence of local variations in thickness combined with the local change of 

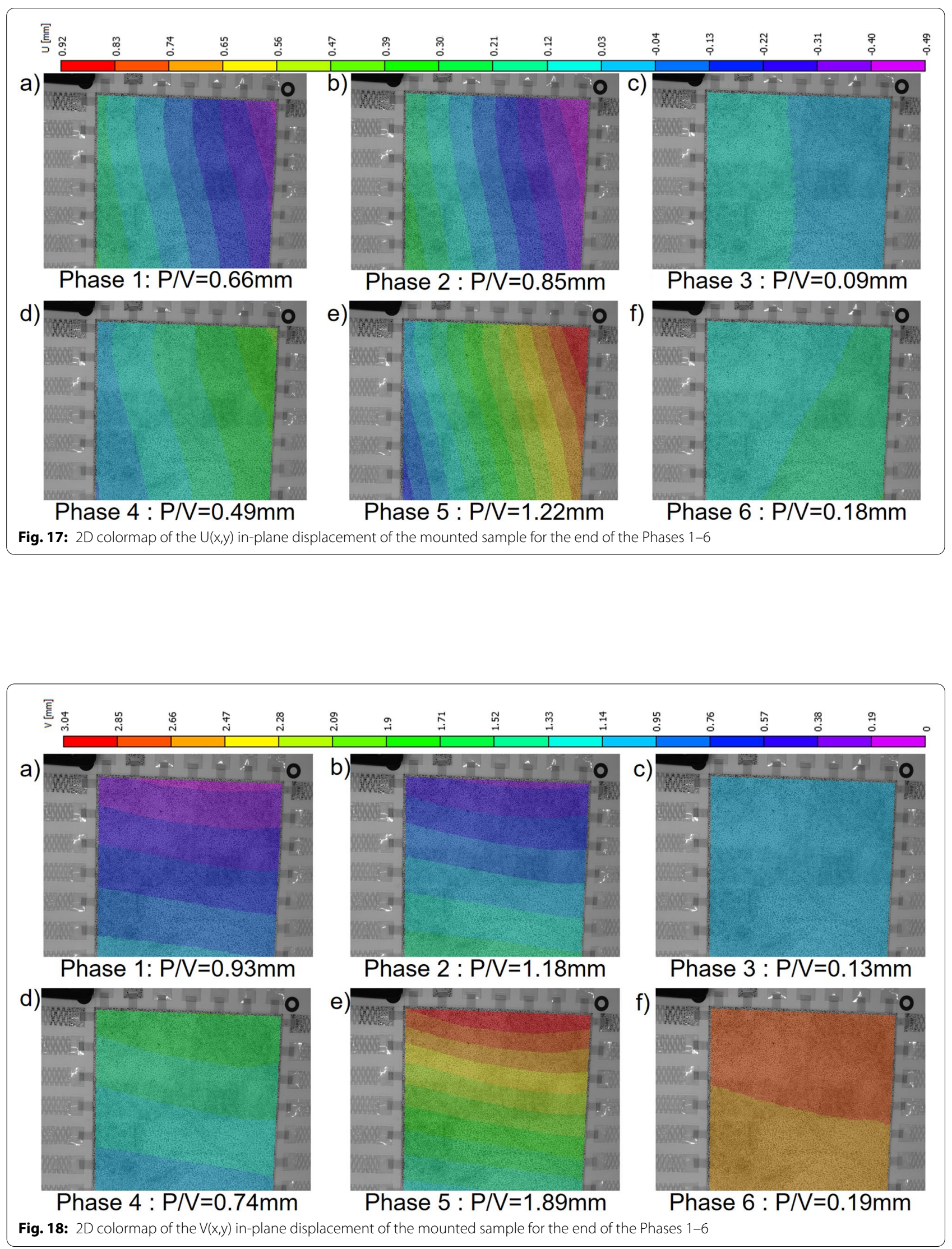


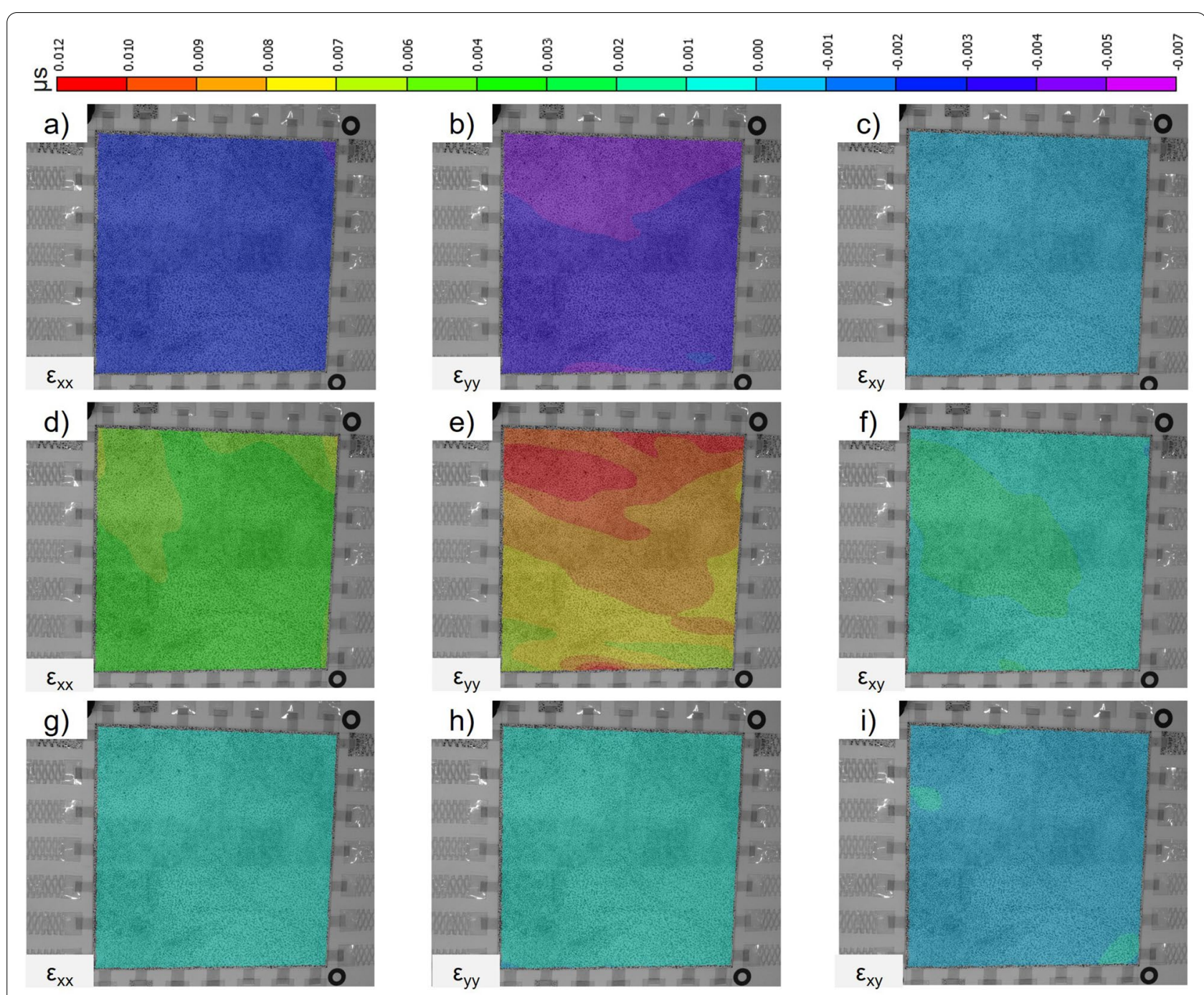

Fig. 19 The strain maps $\varepsilon_{x x^{\prime}} \varepsilon_{y y}$ and $\varepsilon_{x y}$ of the mounted sample calculated for Phase $1(\mathbf{a}-\mathbf{c})$, Phase $5(\mathbf{d}-\mathbf{f})$ and Phase $6(\mathbf{g}-\mathbf{i})$, respectively
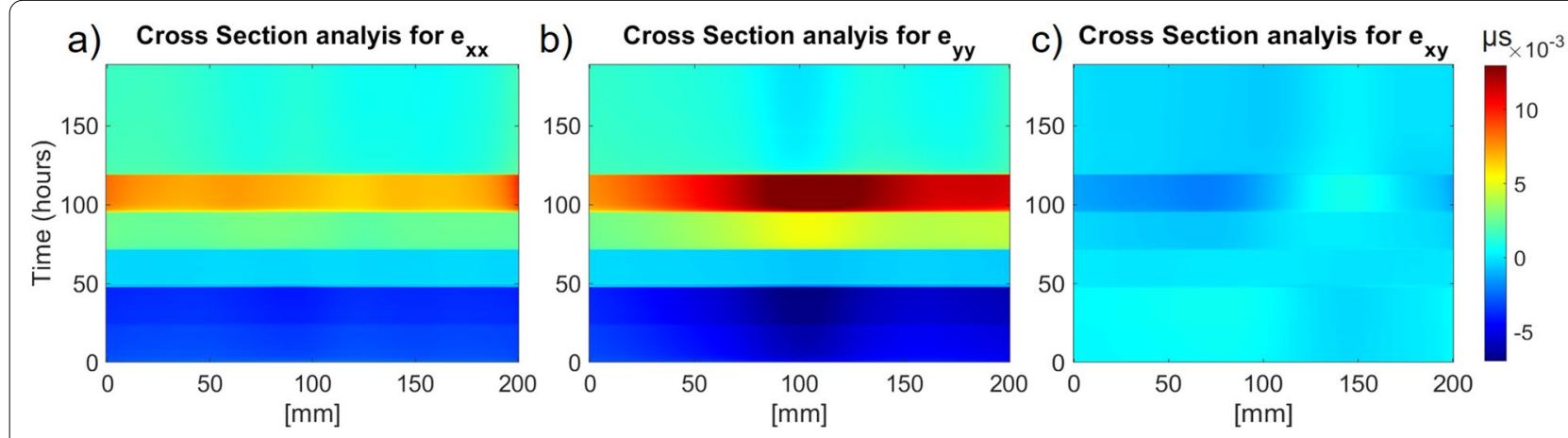

Fig. 20 Spatio-temporal maps of the strains $\mathbf{a} \varepsilon_{x x^{\prime}} \mathbf{b} \varepsilon_{y y}$ and $\mathbf{c} \varepsilon_{x y}$ of the horizontal cross section $L_{0}$ of the unmounted sample 

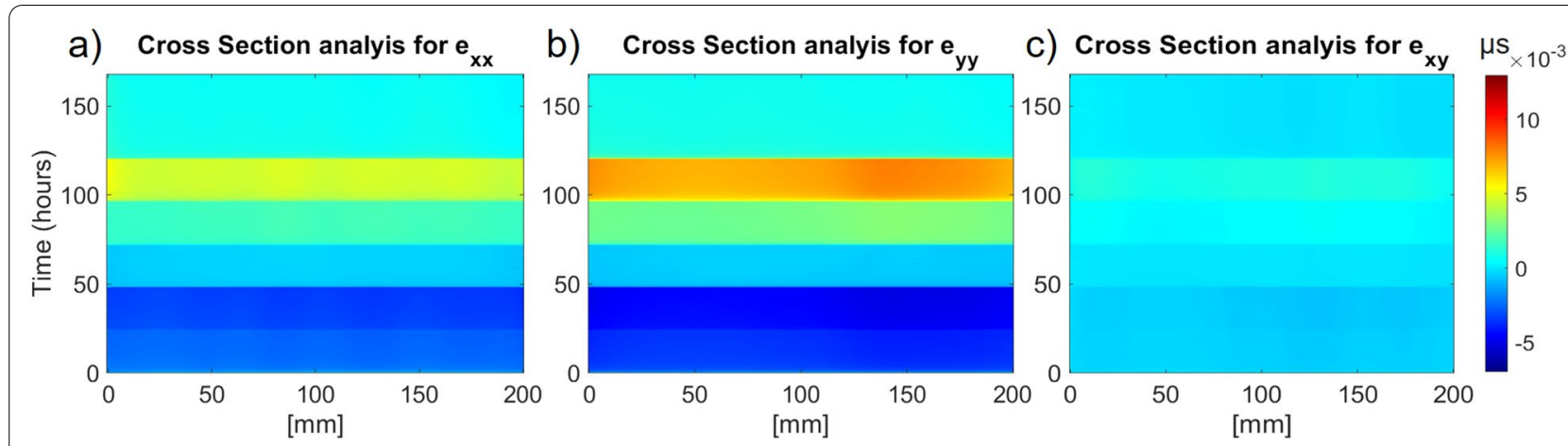

Fig. 21 Spatio-temporal maps of the strains $\mathbf{a} \varepsilon_{x x^{\prime}} \mathbf{b} \varepsilon_{y y}$ and $\mathbf{c} \varepsilon_{x y}$ of the horizontal cross section $L_{0}$ of the mounted sample

fiber's directions on strain values. This is also confirmed through the modulation in $\varepsilon_{x y}$ map (Fig. 20c). Such modulations are not clearly visible in the strain maps of $S_{m}$ (Fig. 21), however the forces introduced through symmetrically located hinges and elastic stripes should have additional influence on the local strain distribution. The reason for lack of information about the strains caused by the mount in Fig. 21 is be due to using of the common colour scale for strains of $S_{u}$ and $S_{m}$ which may hide small strain modulations.

To clarify this issue, the following maps (Figs. 22 and 23) represent 2-h time spans with temporal sampling 4 captures/min of strains in the mounted sample during $\mathrm{RH}$ changes between the sequential RH levels. Note that in Figs. 22 and 23 the colour scale is adjusted for better visualization purposes. The $\varepsilon_{\mathrm{xx}}$ and $\varepsilon_{\mathrm{yy}}$ strain maps indicate that the strains stabilize well within $2 \mathrm{~h}$. The $\varepsilon_{\mathrm{xx}}$ strain map clearly presents the local strain modulations caused by the forces introduced by the hinges and elastic stripes. The maximum amplitude of the additional $\varepsilon_{\mathrm{xx}}$ modulations due to the mount is at the level of $\pm 0.001 \mu \mathrm{s}$ and they are present (with variable amplitude) during all stages of experiment. However these additional strains can be considered in most of the cases as negligible. The

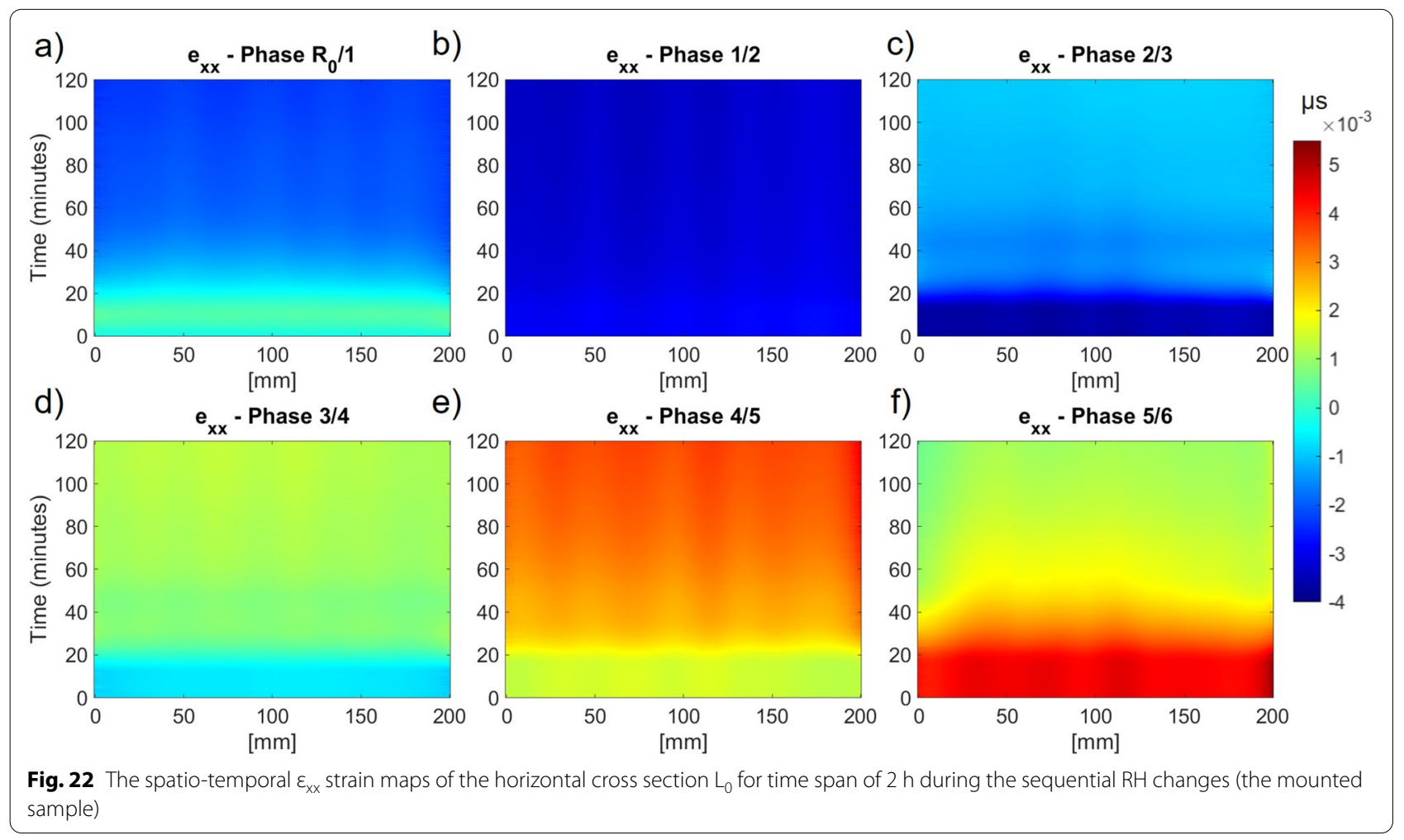




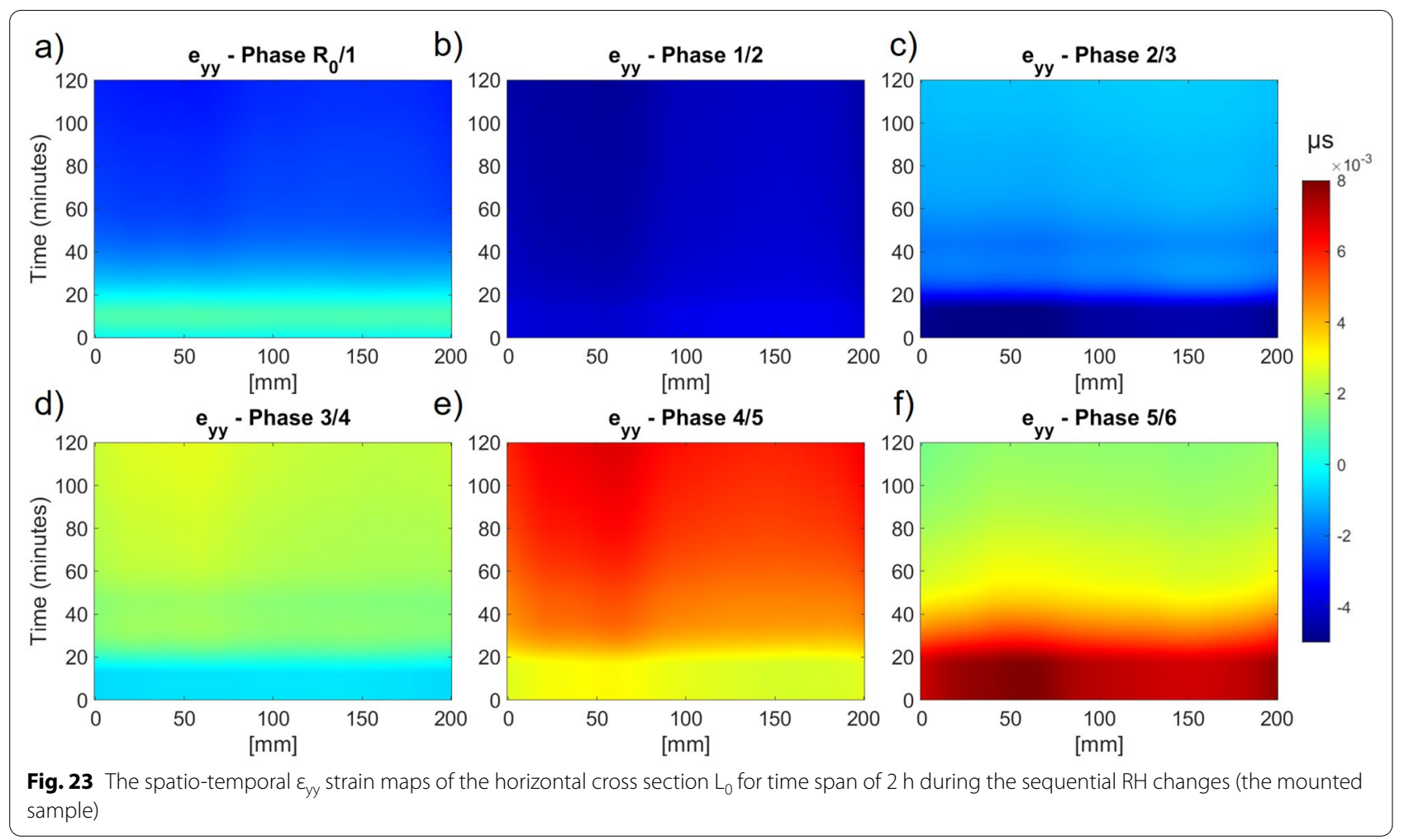

influence of the mount cannot be noticed at $\varepsilon_{\mathrm{yy}}$ strain maps due to the analysis of horizontal cross section (Fig. 23). It was observed that when $\varepsilon_{\mathrm{yy}}$ spatio-temporal map of vertical crossection of $S_{m}$ is analysed, similar modulations occur for the vertical cross section.

\section{Analysis of the global metrics}

Finally to summarize the comparison of the $S_{u}$ and $S_{m}$ mechanical performance during $\mathrm{RH}$ changes we provide the analysis of the global metrics $M(t)$ described in general as the $\mathrm{P} / \mathrm{V}$ of the selected measurand calculated for total area of the sample and for each capture i.e. in the function of time. The compared measurands are the P/V values of W-, U-, V-displacements and $\varepsilon_{\mathrm{xx}}, \varepsilon_{\mathrm{yy}}, \varepsilon_{\mathrm{xy}}$ strains monitored during the full experiment including the final parchment conditioning (Fig. 21).

The $R H(t)$ graphs for $S_{u}$ and $S_{m}$, shown in the in the first raw of Fig. 24, are almost identical, confirming thus that our experimental conditions did not vary for the two samples. The plots of out-of-plane displacements for both samples confirm that the mount minimize W-displacements during all phases of RH changes. The reduction in our case is approx. three fold. What is more, the comparison of the graphs confirms that the mounting system allows the sample to follow its natural out-of plane displacement while supressing its range. The $\mathrm{P} / \mathrm{V}$ of W-displacement returns to its initial value after rehydration process and the final conditioning for the $S_{m}$, while it stays at high values for $S_{u}$. It suggests that the mount compensates for significant hysteresis effect present in $S_{u}$. The plots of $\mathrm{P} / \mathrm{V}$ of in-plane displacements indicate similar global behaviour of both samples, however the $\mathrm{P} / \mathrm{V}$ of $\mathrm{U}$ - and V-displacements for $\mathrm{S}_{\mathrm{m}}$ are smaller and they return to near zero value after final conditioning. This in-plane displacements plots are followed by $\mathrm{P} / \mathrm{V}$ values strain plots. They confirm that the mount system does not increase the strains in the mounted sample, but in contrary it decreases strain values and therefore assures the mechanical stability of the parchment.

\section{Monitoring of displacements in historical parchment: a case study}

A hand written parchment fragmentary from the fourteenth century (?) of unknown origin, was found inside a book cover, serving as a supporting spine strap (Fig. 25a). It had underwent conservation treatment in the past. The historical material has been mounted using the same system as the mock-up sample (Fig. 25b) and subjected $\mathrm{RH}$ change. We decided to avoid extremes and monitor the essential response of the parchment to a small, natural fluctuation of the environmental, namely $\mathrm{RH}$ change from 54 to $41 \%$.

3D DIC analysis was done using a subset of $99 \times 99$ pixels and step of 7 pixels. The subset was approximately 


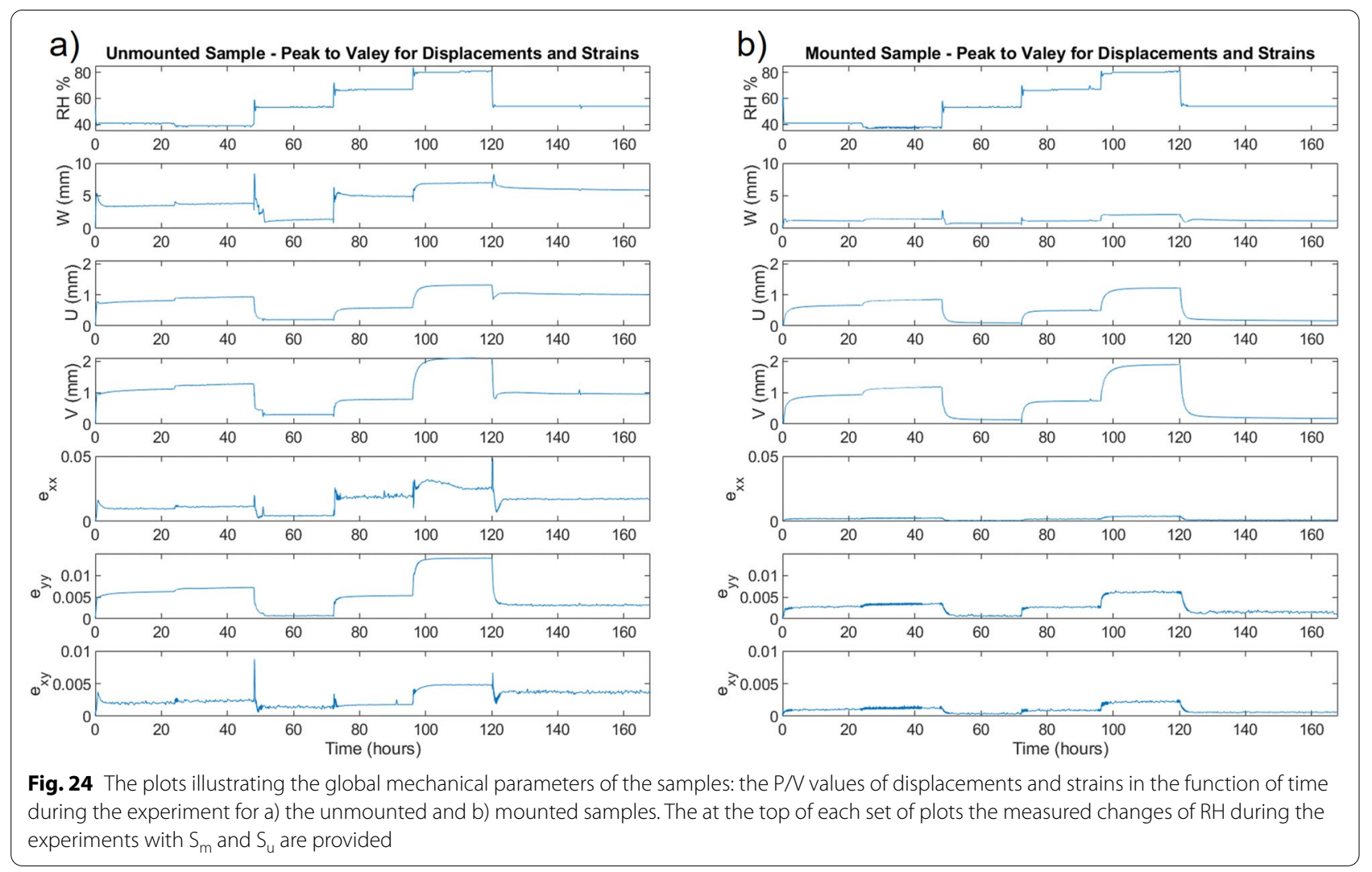

a)

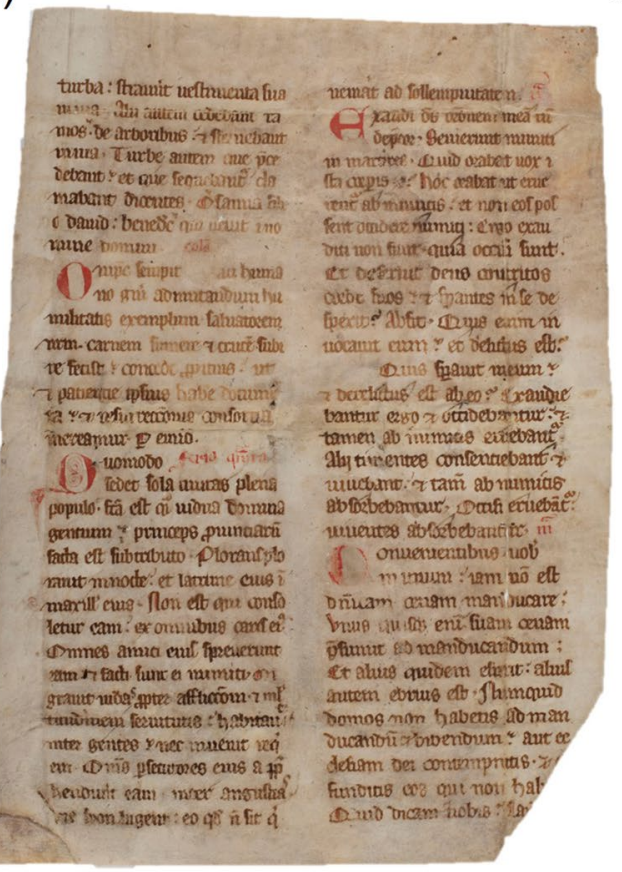

b)

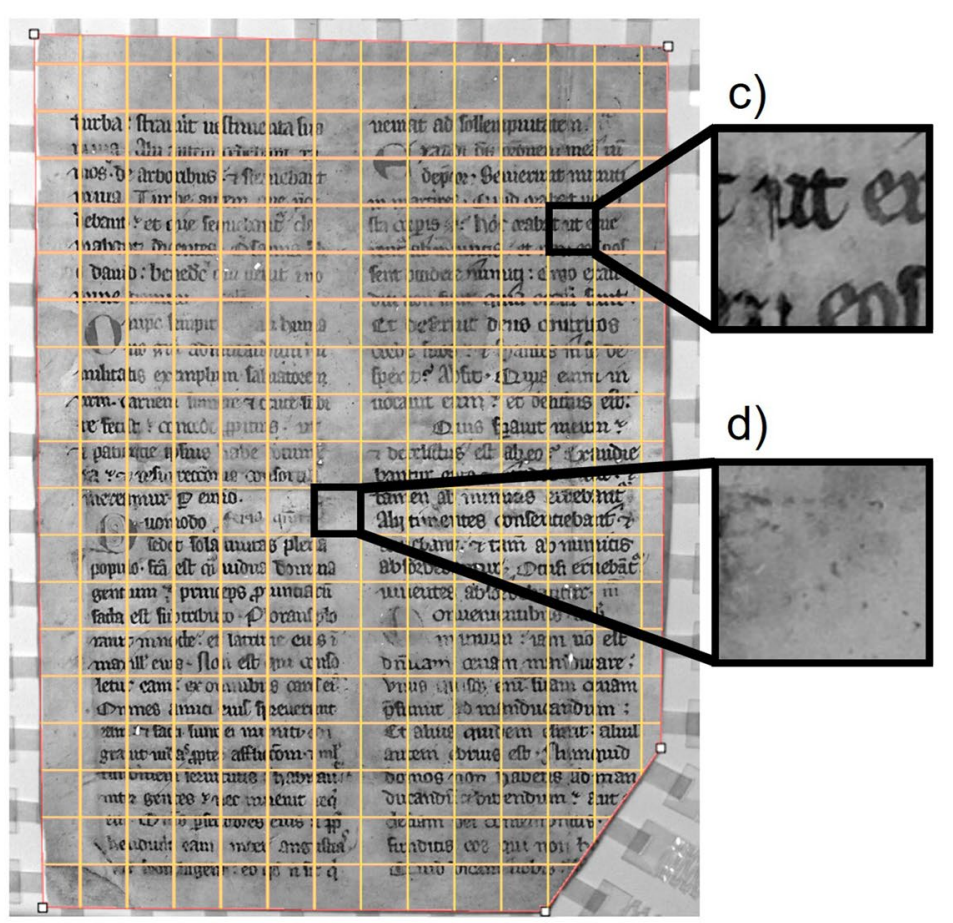

Fig. 25 The Photos of $\mathbf{a}$ the historical manuscript and $\mathbf{b}$ the manuscript after mounting with overlayed net of subsets, $\mathbf{c}$ the subset with high contrast texture and $\mathbf{d}$ the subset with low contrast texture 
three times bigger than the one used for the mock-up sample, but the analysis was still feasible. The squares in Fig. 25b represent the subsets. The intensity distribution shown in Fig. 25c and d indicate the differences in the local, natural texture of the parchment. This is the reason why such samples require larger subsets used for the correlation analysis. In the regions where the contrast and randomness of the texture is low we may expect lower accuracy of displacement measurements or even local lack of calculated results. However the presented case study confirmed the possibility to perform 3D DIC measurements based on images of historical material. It should be mentioned that all kind of additional texture present at historical artefacts in the form of lettering, pictures or local dirt in most of the cases should support the displacement analysis based on digital image correlation method.

Due to the historical character of the sample, we performed a monitoring experiment under environmental fluctuation conditions within the day, which resulted in initial $\mathrm{RH}$ of $54 \%$ and final $\mathrm{RH}$ of $41 \%$. In Fig. 26 we present the example results of $\mathrm{U}, \mathrm{V}$, and $\mathrm{W}$ displacement measurements recorded and calculated for the reference $\mathrm{RH}$ value of $54 \%$ and two different intermediate $\mathrm{RH}$ values: $48 \%$ (Fig. 26a, c, e) and 41\% (Fig. 26b, d, f). Both U and $\mathrm{V}$ in-plane displacements show linear trends with increasing gradient for increasing $\mathrm{RH}$ difference. This confirms the effectiveness of the mounting system which stretch the parchment in order to prevent curling of the material. The values of the out-of-plane displacement also increase with increasing RH difference, however the P/V values are relatively low (Fig. 26e, f).

\section{Conclusions}

It has been the ambition of this study to suggest and implement a full-field measurement method which is able to provide an in-depth evidence for proper selection of the mounting system for display and storage of a single sheet parchments of high historical value. In parallel, the important task of evaluating the effectiveness of stabilizing a single sheet of parchment with the enhanced mounting method which applies elastic polyester strips was undertaken and its realization is confirmed.

Using 3D DIC we were able to record in real time the full field response of parchment mock-ups to fluctuations of the relative humidity, in a non-invasive and non-contact way, without interfering with the climatic chamber processes. We have successfully monitored the out-ofplane and in-plane displacements $(\mathrm{U}, \mathrm{V}, \mathrm{W})$ and strains, that are induced in an unmounted and mounted parchment sample with relative humidity ranging from 39 to

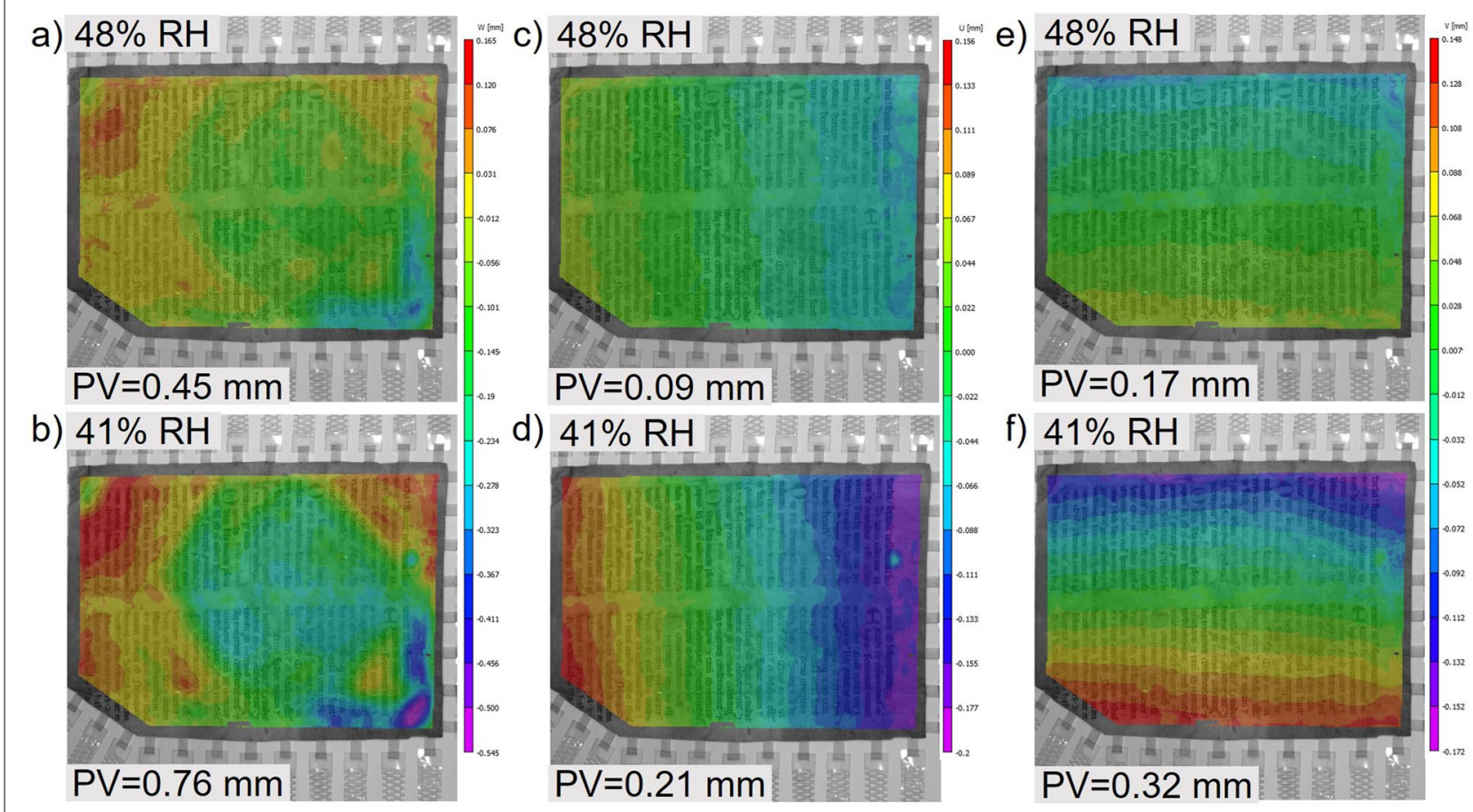

Fig. 26 The colour maps of $\mathbf{a}$, $\mathbf{b}$ out-of-plane $W(x, y)$ displacements and in-plane $\mathbf{c}, \mathbf{d} U(x, y)$ and $, f, f(x, y)$ displacements of the historical parchment for $\mathrm{RH}$ of $48 \%(\mathbf{a}, \mathbf{c}, \mathbf{e})$ and $41 \%(\mathbf{b}, \mathbf{d}, \mathbf{f})$ 
$80 \%$. Both global and local information were analysed either through selected time instances or continuous time spans.

The experiments enabled us to answer the research questions formulated in the introduction of this paper. Through the study of the 3D shape and out-of-plane displacement maps it was possible to track the propagation of the deformation for the selected moisture levels. In this case, the most significant change corresponded to the $80 \%$ of relative humidity, which lead to the maximum detected out-of-plane displacements. The presence of the mounting system suppressed the displacements two folds, while allowing the sample to move similarly to the free-standing one, proving thus its effectiveness. In-plane displacements and strains analysis in the selected time instances, as well as during constant monitoring (spatiotemporal maps) enabled to correlate the inherent material properties (such as fibre directionality, and thickness) with the mechanical response of the sample. As shown by the local and global $(\mathrm{P} / \mathrm{V})$ spatio-temporal analysis the samples remained permanently deformed by the end of the experiment. However, the scale of deformation was a few times lower for the mounted sample. Although, each $\mathrm{RH}$ change deforms the object irreversibly, the proper mounting suppresses the displacements and assists on the safety of the artifact. We have confirmed that the strains level at the mounted sample is kept lower than at the free-standing one and that the deformations and strains introduced locally by the hinges and elastic stripes are negligible. What is more the flexible mount is able to compensate the inhomogeneous mechanical response of the parchment on the variations of $\mathrm{RH}$. The efficiency of the mounting system was proved by each and every analysed aspect, thus allowing to recommend it as a worth considering solution for display and storage of parchment based objects. Monitoring of both: the global and local response of the parchment to the $\mathrm{RH}$ fluctuations gave the opportunity to get insights into the mechanical behaviour of the complex material despite its heterogeneity. One of the main advantages of this versatile optical and low cost measurement technique is that it can be easily adjusted to in situ conditions, i.e. like in our case to position it within a climatic chamber and record without interrupting and alternating the experimental conditions. Of course, there are also limitations connected with 3D DIC, which requires a unique speckle pattern at the surface of the analysed object. The original two mock-up samples used in this study had a very low contrast texture and therefore they could not be analysed with DIC without introducing an artificial speckle pattern at their surface. This would not be permitted for a sample with historical value. However, several cultural heritage objects (including historical parchments) have sufficient natural texture to be analysed but often at the expense of accuracy [58]. In the previous Section of this paper we presented a case study of monitoring displacements of a historical parchment sample without its surface modification. This example confirms the usefulness of the presented methodology of full-field measurements not only for the mock-ups but also for historical material. It should be however mentioned that the accuracy of the measurement depends on the contrast and randomness of the surface texture and therefore the investigations based on natural texture require larger subsets and return lower accuracy results. This is the reason why, a few research groups, including ours, are working on modifications and novel solutions for DIC method with special focus on the needs of cultural heritage objects [59]. Another direction of our work is combining parchment with other coating layers such as paint, that are typically encountered together in cultural heritage in order to study systems of higher complexity that also reflect real situations. The complexity of parchment degradation process also involves taking into account different aspects such as humidity, lighting or temperature influence, therefore widening our group of experimentally modulated parameters should be considered.

In the future, the full-field global and local investigations of historical parchments by 3D DIC should be combined (when required) with microstructural analysis methodologies (FTIR, Raman spectroscopy, DSC, HPLC, SEM-EDS) in order to establish the morphology, define the qualitative and quantitative composition of the material, thermal stability and the degradation of the parchments. Chemical and morphostructural changes and the correlation of the results with the response of the material, will enable more comprehensive interpretation of heterogeneous nature of parchment.

\section{Abbreviations \\ $\mathrm{RH}$ : Relative humidity; $\mathrm{CH}$ : Cultural heritage; DIC: Digital image correlation; CC: Correlation coefficient; PN: Peak to valley; ES: Elastic stripes; SP: Structured panel; EH: External hygrometer; $H$ : Hinge; $S_{m}$ : Sample mounted; $S_{u}$ : Sample unmounted; WUT: Warsaw University of Technology.}

\section{Acknowledgements}

The authors thank Aneta Kukuczka-Szarzec for sharing her work in progress and providing part of Fig. 3. Professor Weronika Liszewska is acknowledged for providing sample of historical parchment.

\section{Authors' contributions}

DD-K prepared the parchment speciments, DD-K, AP and MK designed the experiments, DD-K and AP conducted the experiments, AP computed the results, all authors interpreted the results, all authors wrote the manuscript. All authors read and approved the final manuscript.

\section{Authors' information}

Athanasia Papanikolaou received her master's in Photonics and Nanoelectronics from the University of Crete. Currently she is a PhD Candidate at Warsaw University of Technology and a Marie Curie ITN fellow at the EU project CHANGE. Her work is focused on the development of a portable multimodal 
device for surface analysis and monitoring of cultural heritage objects. Dorota Dzik-Kruszelnicka holds a PhD Degree in conservation. She has been working at the Department of Book and Paper Conservation, Faculty of Conservation and Restoration of Works of Art, Academy of Fine Arts in Warsaw since 2010 and as a conservator at the National Museum in Warsaw since 2007. She has been involved in several conservation and research projects and is the author of many publications on paper conservation. Malgorzata Kujawinska PhD DSc., SPIE Fellow, Full Professor of applied optics at Warsaw University of Technology. International expert in full-field optical metrology, development of novel photonics measurement systems, 3D quantitative imaging in engineering, cultural heritage and biomedicine. Author of one monograph, several book chapters and more than 250 papers in international scientific journals. The recipient of SPIE 2013 C.S.Vikram Award in Optical Metrology and SPIE 2021 D.Gabor Award in Diffractive Optics.

\section{Funding}

This work is carried out at the beneficiary partner of CHANGE: Cultural Heritage Analysis for New Generation, Warsaw University of Technology, Poland, received funding from the European Union's Horizon 2020 research and innovation program under the Marie Skłodowska-Curie grant agreement No. 813789 . The project has received financial support by the Scientific Council of the Discipline Automatic, Electronics and Electrical Engineering, of Warsaw University of Technology, grant agreement No 504/04542/1143/43.020004. This study was also supported by the statutory research fund of the Academy of Fine Arts in Warsaw, Poland [WK/Dorota Dzik-Kruszelnicka-młody naukowiec (2020), WK/01/MN (2021)].

\section{Availability of data and materials}

The data used and/or analysed during the current study are available from the corresponding author on reasonable request.

\section{Declarations}

\section{Competing interests}

The authors declare that they have no competing interests.

\section{Author details}

${ }^{1}$ Faculty of Mechatronics, Warsaw University of Technology, Warsaw, Poland.

${ }^{2}$ Faculty of Conservation and Restoration of Works of Art, Academy of Fine Arts, Warsaw, Poland.

Received: 24 September 2021 Accepted: 11 January 2022 Published online: 25 January 2022

\section{References}

1. Reed R. The nature and making of parchment. Leeds: Elmete; 1975.

2. Odlyha M. Introduction to the preservation of cultural heritage. J Therm Anal Calorim. 2011;104:399-403. https://doi.org/10.1007/ s10973-011-1421-0.

3. Odlyha M, Cohen N, Foster G, Campana R. Characterization of historic and unaged parchments using thermomechanical and thermogravimetric techniques. In: Larsen R, editor. Microanalysis of Parchment. London: Archetype Publications; 2002. p. 73-89.

4. Larsen R, European Comission, Directorate-General for Research, Directorate I--Environment. Improved damage assessment of parchment IDAP : assessment, data collection and sharing of knowledge. Luxembourg: European Commission, Directorate-General for Research, Directorate I--Environment; 2007.

5. Badea E, Della Gatta G, Budrugeac P. Characterisation and evaluation of the environmental impact on historical parchments by differential scanning calorimetry. J Therm Anal Calorim J Therm Anal Calorim. 2011;104:495-506. https://doi.org/10.1007/s10973-011-1495-8.

6. Liszewska W. New methods of leafcasting in the conservation of historic parchments. 2017.

7. Popescu CM, Hill C, Kennedy C. Variation in the sorption properties of historic parchment evaluated by dynamic water vapour sorption. J Cult Herit. 2016;17:87-94. https://doi.org/10.1016/j.culher.2015.06.001.
8. Gonzalez LG, Wess TJ. The effects of hydration on the collagen and gelatine phases within parchment artefacts. Herit Sci. 2013;1:14. https://doi. org/10.1186/2050-7445-1-14.

9. Hansen EF, Lee SN, Sobel H. The effects of relative humidity on some physical properties of modern vellum: implications for the optimum relative humidity for the display and storage of parchment. J Am Inst Conserv. 1992;31:325-42. https://doi.org/10.1179/019713692806066600.

10. Facchini A, Malara C, Bazzani G, Cavallotti PL. Ancient parchment examination by surface investigation methods. J Colloid Interface Sci. 2000;231:213-20. https://doi.org/10.1006/jcis.2000.7138.

11. Woods CS. The conservation of parchment. In: Kite M, Thomson R, editors. Conserv. Leather Relat. Mater, Routledge; 2005. p. 200-221. https://doi. org/10.4324/9780080454665.

12. Kennedy CJ, Wess TJ. The Structure of Collagen within Parchment-a Review. Restaurator. 2003;24:61-80. https://doi.org/10.1515/REST.2003.61.

13. Florian MLE. The mechanism of deterioration in leather. In: Kite $M$, Thomson R, editors. Conserv. Leather Relat. Mater., 2005. https://doi.org/10. 4324/9780080454665.

14. Možir A, Cigić IK, Marinšek M, Strlič M. Material properties of historic parchment: a reference collection survey. Stud Conserv. 2014;59:136-49. https://doi.org/10.1179/2047058413Y.0000000100.

15. Axelsson KM, Larsen R, Sommer DVP, Melin R. Degradation of collagen in parchment under the influence of heat-induced oxidation: Preliminary study of changes at macroscopic, microscopic, and molecular levels. Stud Conserv. 2016;61:46-57. https://doi.org/10.1179/2047058414Y.00000 00140.

16. Krzemień L, Czyżewska A, Soboń M, Kozłowski R, Bratasz Ł. Risk of climate-induced damage in historic parchment. Herit Sci. 2020;8:17. https://doi.org/10.1186/s40494-020-0360-0.

17. Kosek JM. Conservation Mounting for Prints and Drawings. 1st ed. London: Archetype Publications Ltd; 2004.

18. Pickwoad N. Alternative methods of mounting parchment for framing and exhibition. Pap Conserv. 1992;16:78-85. https://doi.org/10.1080/ 03094227.1992 .9638579$.

19. Norman D. The mounting of single leaf parchment \& vellum objects for display and storage. Conserv J 1993.

20. Grossman A. The Gantse Megillah: Conservation of a 14-15th Century Parchment Esther Scroll, 1997.

21. Maver I. An alternative method of mounting and displaying large parchment membranes Paper Conserv News 2000;8-11.

22. Lawson M. A method of mounting parchment using hair silk. J Am Inst Conserv. 2004:43:175-84. https://doi.org/10.1179/019713604806082537.

23. Rayner J, Kosek J, Christensen B, editors. Art on Paper: Mounting and Housing. London: Archetype Publications Ltd; 2018.

24. Rickman C, Edmondson K, Le Cornu E. The conservation of botanical illustrations on vellum: past, present and future. J Inst Conserv. 2012;35:11736. https://doi.org/10.1080/19455224.2012.724606.

25. Konstantinidou K. Hanging by a thread?: a housing/display suggestion for single parchment leaves without the use of adhesive. J Pap Conserv. 2014;15:24-7.

26. Duqueyroix N, Robinet $L$, Barbe $C$. Expandable polyester hinges for parchment mounting performance in fluctuating environmental conditions. J Pap Conserv. 2015;16:18-28. https://doi.org/10.1179/1868086015Z.00000 00002.

27. Szczepanowska HM. Conservation of Cultural Heritage: Key Principles and Approaches. 1st ed. London: Routledge; 2012. https://doi.org/10.4324/ 9780203081198.

28. Clarkson C, Preservation and Display of Single Parchment Leaves and Fragments. In: Petheridge G, editor. Int. Conf. Conserv. Libr. Arch. Mater. Graph. Arts, Cambridge: London : Institute for Paper Conservation. Society of Archivists 1980; p. 201-209.

29. ICA Committee on Preservation of Archives in Temperate Climates (CPTE 2002-2006) "Guidlines ong exhibiting archival materials", 2006:66. https:// www.ica.org/en/guidelines-exhibiting-archival-materials Accessed 23 Sept 2021

30. D`Alessandro E. Using Expandable Polyester Hinges to Mount a Doublesided Parchment Folio. http://www.pzconservation.org.uk/2018/05/ using-expandable-polyester-hinges-to.html Accessed 23 Sept 2021

31. Morin C, Hellmich C, Henits P. Fibrillar structure and elasticity of hydrating collagen: a quantitative multiscale approach. J Theor Biol. 2013;317:38493. https://doi.org/10.1016/j.jtbi.2012.09.026. 
32. Masic A, Bertinetti L, Schuetz R, Chang SW, Metzger TH, Buehler MJ, et al Osmotic pressure induced tensile forces in tendon collagen. Nat Commun. 2015;6:5942. https://doi.org/10.1038/ncomms6942.

33. Pal K, Terras M, Weyrich T. $3 D$ reconstruction for damaged documents: imaging of the Great Parchment Book. In: Märgner V, Frinken V, Barret B, editors. 2nd International Workshop on Historical Document Imaging and Processing (HIP'13), 2013. New York: Association for Computing Machinery; 2013. p. 14-21 https://doi.org/10.1145/2501115.2501125.

34. Sutton MA, Orteu JJ, Schreier H. Image Correlation for Shape, Motion and Deformation Measurements. New York: Springer US; 2009. https://doi. org/10.1007/978-0-387-78747-3.

35. Haines BM. Parchment: The Physical and Chemical Characteristics of Parchment and the Materials Used in Its Conservation. Leather Conservation Centre; 1999

36. Haines BM. Collagen: the leather making protein. In: Kite M, Thomson R, editors. Conserv. Leather Relat. Mater., London: Routledge; 2006.

37. Perskór n.d. http://www.perskor.pl/ofirmie.php. Accessed 23 Sept 2021

38. BESKID. Poliester Melinex Certificat 2021. https://beskidplus.com.pl/public/upload/source/DOWNLOAD/Certyfikaty/PL/MELINEX_CERTYFIKAT_PL. PDF. Accessed 23 Sept 2021

39. Pan B. Recent progress in digital image correlation. Exp Mech. 2011;51:1223-35. https://doi.org/10.1007/s11340-010-9418-3.

40. Orteu JJ. 3-D computer vision in experimental mechanics. Opt Lasers Eng. 2009;47:282-91. https://doi.org/10.1016/j.optlaseng.2007.11.009.

41. Malesa M, Malowany K, Tomczak U, Siwek B, Kujawińska M, SiemińskaLewandowska A. Application of 3D digital image correlation in maintenance and process control in industry. Comput Ind. 2013;64:1301-15. https://doi.org/10.1016/j.compind.2013.03.012.

42. Cunha FG, Santos TG, Xavier J. In situ monitoring of additive manufacturing using digital image correlation: a review. Materials (Basel). 2021. https://doi.org/10.3390/ma14061511.

43. Ramos T, Furtado A, Eslami S, Alves S, Rodrigues H, Arêde A, et al. 2D and $3 \mathrm{D}$ digital image correlation in civil engineering - measurements in a masonry wall. Procedia Eng. 2015;114:215-22. https://doi.org/10.1016/j. proeng.2015.08.061.

44. Malowany K, Piekarczuk A, Malesa M, Kujawińska M, Więch P. Application of $3 \mathrm{D}$ digital image correlation for development and validation of fem model of self-supporting arch structures. Appl Sci. 2019. https://doi.org/ 10.3390/app9071305.

45. Malesa M, Malowany K, Tymińska-Widmer L, Kwiatkowska EA, Kujawńska $M$, Rouba BJ, et al. Application of digital image correlation (DIC) for tracking deformations of paintings on canvas. Proc.SPIE, 8084, 2011. https:// doi.org/10.1117/12.889452.

46. Malowany K, Tymińska-Widmer L, Malesa M, Kujawińska M, Targowski P, Rouba BJ. Application of 3D digital image correlation to track displacements and strains of canvas paintings exposed to relative humidity changes. Appl Opt. 2014;53:1739-49. https://doi.org/10.1364/AO.53. 001739.

47. Sutton MA, Matta F, Rizos D, Ghorbani R, Rajan S, Mollenhauer DH, et al. Recent progress in digital image correlation: background and developments since the 2013 W M Murray Lecture. Exp Mech. 2017;57:1-30. https://doi.org/10.1007/s11340-016-0233-3.

48. Pan B, Qian K, Xie H, Asundi A. Two-dimensional digital image correlation for in-plane displacement and strain measurement: a review. Meas Sci Technol. 2009;20:62001. https://doi.org/10.1088/0957-0233/20/6/062001.

49. Dong $Y L$, Pan B. A review of speckle pattern fabrication and assessment for digital image correlation. Exp Mech. 2017;57:1-21. https://doi.org/10. 1007/s11340-017-0283-1.

50. Hild F, Raka B, Baudequin M, Roux S, Cantelaube F. Multiscale displacement field measurements of compressed mineral-wool samples by digital image correlation. Appl Opt. 2002;41:6815-28. https://doi.org/10. 1364/AO.41.006815.

51. Papanikolaou A, Dzik - Kruszelnicka D, Saha S, Kujawińska M. 3D digital image correlation system for monitoring of changes induced by $\mathrm{RH}$ fluctuations on parchment. Electron. Imaging, Society for Imaging Science and Technology; 2021. https://doi.org/10.2352/ISSN.2470-1173.2021.18. 3DIA-065.

52. CTS. Climatic Test Chambers / C-40 and C-70 - Product Specifications. https://www.cts-umweltsimulation.de/images/produkte/ps-baureihe-c/ download/CTS_Climatic_Test_Chambers_eng.pdf. Accessed 23 Sept 2021
53. VIC 3D v7 Reference Manual, Correlated Solutions 2016. http://www.corre latedsolutions.com/supportcontent/Vic-3D-v7-Manual.pdf Accessed 23 Sept 2021

54. Dernovšková J, Jirasová H, Zelinger J. An investigation of the hygroscopicity of parchment subjected to different treatments. Restaurator. 1995;16:31-44. https://doi.org/10.1515/rest.1995.16.1.31.

55. Badea E, Vetter W, Petroviciu I, Carsote C, Miu L, Schreiner M, et al. How parchment responds to temperature and relative humidity: a combined micro DSC, MHT, SEM and ATR-FTIR study. In: Albu L, Deselnicu V, editors. Proceedings of the 4th International Conference on Advanced Materials and Systems, 2012. Romania: INCDTP-ICPI 2012. p487-492

56. Kern MS, Pataki-Hundt A, Wouters J, Kirby DP. Accelerated ageing of parchment: investigation of a photo catalysed, low-heat approach. Restaur Int J Preserv Libr Arch Mater. 2018;39:33-70. https://doi.org/10.1515/ res-2017-0013.

57. Badea E, Della Gatta G, Usacheva T. Effects of temperature and relative humidity on fibrillar collagen within parchment: a micro Differential Scanning Calorimetry (micro DSC) study. Polym Degrad Stab. 2012. https:// doi.org/10.1016/j.polymdegradstab.2011.12.013.

58. Kujawinska M, Malesa M, Malowany K, Piekarczuk A, Tymińska-Widmer L, Targowski P. Digital image correlation method: a versatile tool for engineering and art structures investigations. Proc.SPIE, vol. 8011, 2011. https://doi.org/10.1117/12.915566.

59. Papanikolaou A, Garbat P, Kujawińska M. Colour digital image correlation method for monitoring of cultural heritage objects with natural texture. Proc.SPIE, vol. 11784, 2021.

\section{Publisher's Note}

Springer Nature remains neutral with regard to jurisdictional claims in published maps and institutional affiliations.

\section{Submit your manuscript to a SpringerOpen ${ }^{\circ}$ journal and benefit from:}

- Convenient online submission

- Rigorous peer review

- Open access: articles freely available online

- High visibility within the field

- Retaining the copyright to your article

Submit your next manuscript at $\boldsymbol{\nabla}$ springeropen.com 